\title{
Interannual Variability of Northwest Australian Tropical Cyclones
}

\author{
KEVIN H. GOEBBERT \\ School of Meteorology, University of Oklahoma, Norman, Oklahoma, and Department of Geography \\ and Meteorology, Valparaiso University, Valparaiso, Indiana \\ LANCE M. LESLIE \\ School of Meteorology, University of Oklahoma, Norman, Oklahoma, and Australian Institute \\ for Sustainable Development, Curtin University, Perth, Western Australia, Australia
}

(Manuscript received 30 July 2009, in final form 26 April 2010)

\begin{abstract}
Tropical cyclone (TC) activity over the southeast Indian Ocean has been studied far less than other TC basins, such as the North Atlantic and northwest Pacific. The authors examine the interannual TC variability of the northwest Australian (NWAUS) subbasin $\left(0^{\circ}-35^{\circ} \mathrm{S}, 105^{\circ}-135^{\circ} \mathrm{E}\right)$, using an Australian $\mathrm{TC}$ dataset for the 39-yr period of 1970-2008. Thirteen TC metrics are assessed, with emphasis on annual TC frequencies and total TC days.

Major findings are that for the NWAUS subbasin, there are annual means of 5.6 TCs and 42.4 TC days, with corresponding small standard deviations of 2.3 storms and 20.0 days. For intense TCs (WMO category 3 and higher), the annual mean TC frequency is 3.0, with a standard deviation of 1.6 , and the annual average intense TC days is 7.6 days, with a standard deviation of 4.5 days. There are no significant linear trends in either mean annual TC frequencies or TC days. Notably, all 13 variability metrics show no trends over the 39 -yr period and are less dependent upon standard El Niño-Southern Oscillation (ENSO) variables than many other TC basins, including the rest of the Australian region basin. The largest correlations with TC frequency were geopotential heights for June-August at $925 \mathrm{hPa}$ over the South Atlantic Ocean $(r=-0.65)$ and for April-June at $700 \mathrm{hPa}$ over North America ( -0.64$)$. For TC days the largest correlations are geopotential heights for July-September at $1000 \mathrm{hPa}$ over the South Atlantic Ocean $(-0.7)$ and for April-June at $850 \mathrm{hPa}$ over North America $(-0.58)$. Last, wavelet analyses of annual TC frequencies and TC days reveal periodicities at ENSO and decadal time scales. However, the TC dataset is too short for conclusive evidence of multidecadal periodicities.

Given the large correlations revealed by this study, developing and testing of a multivariate seasonal TC prediction scheme has commenced, with lead times up to 6 months.
\end{abstract}

\section{Introduction}

Tropical cyclones (TCs) annually threaten life and property in affected areas of the globe. Prior to modern meteorological sensing instrumentation, TCs often hit coastal areas with little or no warning. Without comprehensive data coverage it is difficult to ascertain TC location and intensity. For example, Galveston, Texas, was devastated in 1900 with minimal advance warning (Larson 2000). Even with present advanced remote sensing technology, TC impacts often are misestimated.

Corresponding author address: Kevin H. Goebbert, Department of Geography and Meteorology, Valparaiso University, 1809 Chapel Dr., Valparaiso, IN 46383.

E-mail: kevin.goebbert@valpo.edu
The American Meteorological Society glossary defines a TC as a disturbance originating over tropical oceans (Glickman 2000). Gray (1968) more precisely defines a tropical storm as a "warm-core cyclonically rotating wind system in which maximum sustained winds are $17 \mathrm{~m} \mathrm{~s}^{-1}$ (35 kt; $40 \mathrm{mph}$ ) or greater." The Australian Bureau of Meteorology (BOM) categorizes TCs by maximum 10-min sustained wind (wind gusts) into five severity categories: 1) 63-88 (91-125) $\mathrm{km} \mathrm{h}^{-1}$;2) 89-117 (125-164) $\mathrm{km} \mathrm{h}^{-1}$; 3) 118-159 (165-224) $\mathrm{km} \mathrm{h}^{-1}$; 4) 160-200 (225279) $\mathrm{km} \mathrm{h}^{-1}$; and 5) greater than 200 (279) $\mathrm{km} \mathrm{h}^{-1}$ (BOM 2010). Australian region TCs are named when they exhibit 10-min, 10-m sustained wind speeds greater than $17 \mathrm{~m} \mathrm{~s}^{-1}$, spanning more than $50 \%$ of the storm.

The year-to-year variations of TCs in any TC basin can be described by a range of different metrics. Common 


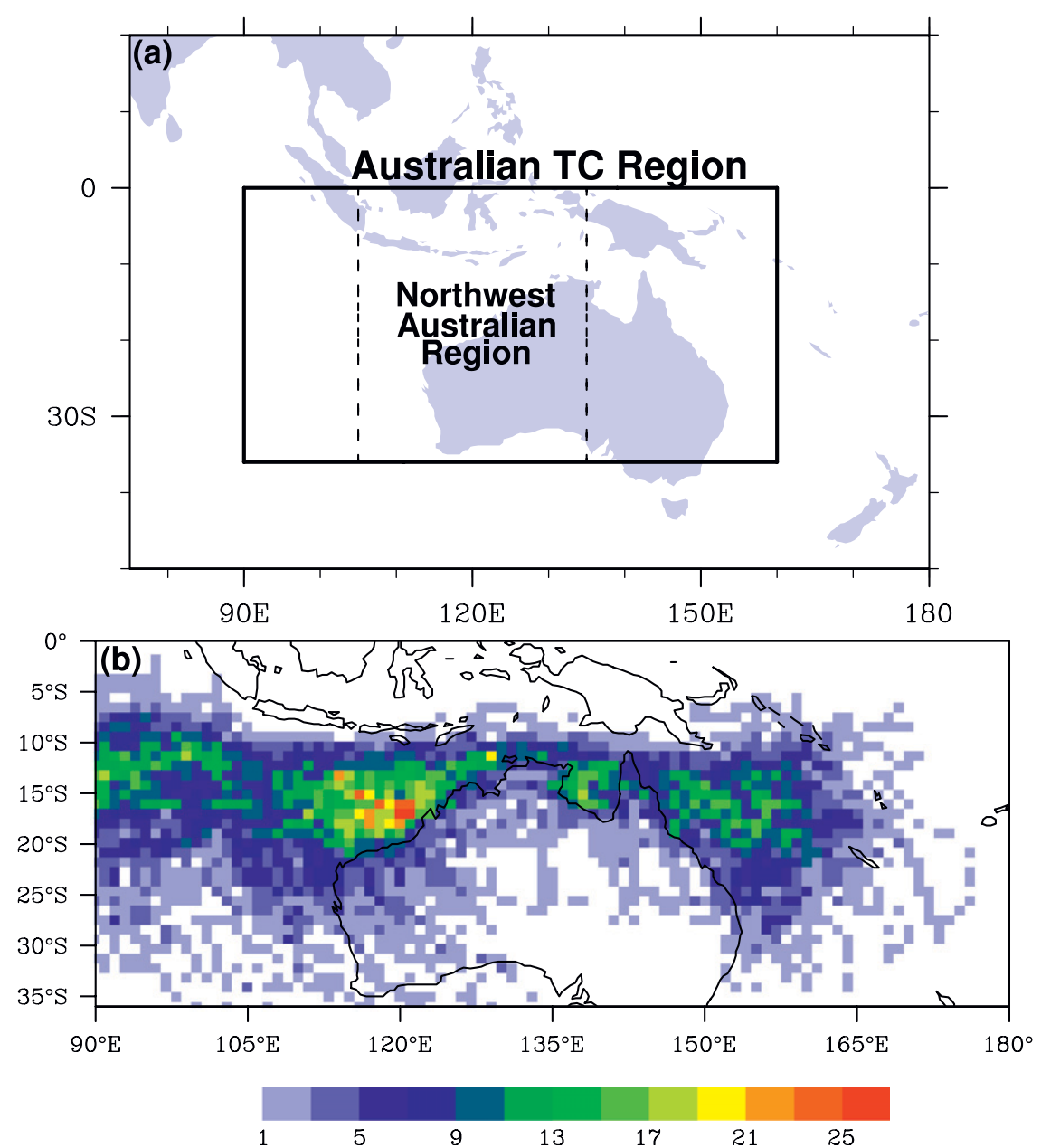

FIG. 1. Map of the (a) Australian TC region $\left(35^{\circ} \mathrm{S}-0^{\circ}, 90^{\circ}-160^{\circ} \mathrm{E}\right)$, with the northwest Australian region $\left(105^{\circ}-135^{\circ} \mathrm{E}\right)$ identified between the dashed lines and (b) number of TCs that crossed into each $1^{\circ}$ latitude $\times 1^{\circ}$ longitude box within the entire Australian region during the period 1970-2008. The TC data used to construct this map was compiled from the Australian BOM best-track dataset.

metrics are TC frequency, TC days (TCDs), accumulated cyclone energy (ACE), and power dissipation index (PDI). Recently, focus is on the role of global atmospheric and oceanic parameters in describing TC variability on multiyear to multidecadal time scales (e.g., Nicholls 1992; Chan 1985; Solow and Nicholls 1990; Gray et al. 1992; Evans and Allan 1992; Gray et al. 1993; Nicholls et al. 1998; Chan and Liu 2004; Klotzbach and Gray 2004; Ramsay et al. 2008).

The TC basins of the Southern Hemisphere have not been studied as extensively as the North Atlantic and western North Pacific TC basins. The Australian TC ba$\sin \left(90^{\circ}-170^{\circ} \mathrm{E}, 0^{\circ}-35^{\circ} \mathrm{S}\right.$; Fig. 1a) typically has been investigated as a single TC basin (e.g., Nicholls 1979, 1984, 1985, 1992; Evans and Allan 1992; Nicholls et al. 1998; Hall et al. 2001; Ramsay et al. 2008). To better understand different aspects of the Australian region, it is advantageous to define TC regions based on climatological considerations. However, few studies have focused on just one of the two primary subbasins of the Australian TC region: the southwest Pacific (SWPAC) Ocean basin $\left(135^{\circ}-170^{\circ} \mathrm{E}\right)$ (e.g., Revell and Goulter 1986; Hastings 1990; Basher and Zheng 1995) and the southeast Indian (SEIND) Ocean basin $\left(90^{\circ}-135^{\circ} \mathrm{E}\right)$ (e.g., Broadbridge and Hanstrum 1998). This study concentrates only on the northwest Australian (NWAUS) TC basin, itself a subbasin of the SEIND Ocean (Fig. 1a). This basin is a major economic region of Australia, as a source of commodities (e.g., oil, natural gas, and iron ore), whose production frequently is disrupted by TC activity.

The NWAUS TC basin is the most active Australian subbasin (Fig. 1b), and its boundaries are identified by 
local minima in mean TC frequency near longitudes $105^{\circ}$ and $135^{\circ} \mathrm{E}$. This climatologically driven definition of a TC basin may be more likely to have uniform characteristics of large-scale patterns describing the variability with the region. An understanding of and capacity to predict the seasonal variability of TC metrics is needed to limit the impact of a TC season. In addition to impacted industries, rainfall from landfalling TCs in the NWAUS basin is a freshwater source for northwest Australia.

Previous work in the Australian region did not focus on the NWAUS TC subbasin, but on the entire Australian TC basin and the role of El Niño-Southern Oscillation (ENSO). However, there is increasing awareness of other global teleconnections in modulating TC activity worldwide. Studies of the Atlantic and northwest Pacific TC basins have identified parameters, aside from ENSO variables, important in describing the interannual variability of TC frequency (e.g., Gray 1984a,b; Gray et al. 1992, 1993; Chan 1985; Chan et al. 1998; Klotzbach and Gray 2003). For the Atlantic and NWPAC TC basins, they include the quasi-biennial oscillation (QBO), AsianAustralian monsoon, Caribbean sea level pressure, and November 500-hPa geopotentials.

Here, NWAUS TC metric variability is determined primarily, but not only, from interannual and longer period variability of mean annual TC frequency and TC days. An attempt is made to identify the global modes or atmospheric parameters that contribute most to explaining observed NWAUS TC variance. These global teleconnections are not limited to the Southern Hemisphere but are intrabasin, interbasin, and cross hemispheric. Finally, preliminary results are presented from using a multiple linear regression model for seasonal prediction of NWAUS TC frequency and TC days.

\section{Data and methodology}

TC observations have improved significantly with the aid of satellites, which have advanced the meteorological understanding of what is and is not a TC. However, despite improved observing technology, including advanced wind observing satellites, debate continues about how individual storms should be classified. The mean number of global TCs has been estimated to be 90 TCs per year (Frank and Young 2007), with a relatively small standard deviation of 10 (Lander and Guard 1998), for TCs with sustained wind speeds $>17 \mathrm{~m} \mathrm{~s}^{-1}$ (34 kt).

\section{a. TC data and data quality}

Australian TC observations date back to the early nineteenth century, with reliable observations dating from the satellite era, beginning around 1970 (Holland 1981). Hence, only TCs from the 1970/71 TC season are used here. However, some observations, especially of TC intensity, remain questionable. Holland (1981), Nicholls et al. (1998), and Buckley et al. (2003) discuss changes in TC definition, analysis techniques, satellite technology, radar coverage, and in situ observations. Most TC dataset problems are not mutually exclusive; frequently a better understanding of TCs led to changes in analysis techniques and TC definitions. The regular use of satellites began in 1966 and for geostationary satellites in 1978 (Holland 1981). Even today there are limited in situ observations of TCs in the Australian region, especially for TCs that never make landfall, and there is no regular aircraft reconnaissance (Landsea 2000).

To account for shortcomings in the NWAUS region TC dataset, a reanalysis was undertaken by Harper et al. (2008). This study was commissioned by Woodside Petroleum Ltd. (WPL) and specifically covers the TC region investigated in this paper. Another reanalysis has been started by Trewin (2008) to account for inconsistencies in the official Australian BOM TC dataset. A comparison of the two datasets for two key TC metrics, TC frequency and TC days, reveals that the datasets are highly correlated with each other. However, the Harper et al. (2008) dataset was chosen over the revised BOM dataset (Trewin 2008), largely because it provides a consistently analyzed record from at least the 1970/71 TC season with observations consistently available at 0000 , 0600, 1200, and 1800 UTC, and with estimated wind speeds for each observation. A drawback with the BOM dataset is its lack of consistent observations for many TCs. For example, some TCs have wind speed observations, while others do not. The times of observations are also not consistent over the dataset, with some TCs having observations every hour, three hours, six hours, or even just once a day. The benefits of consistency of the Harper et al. (2008) dataset are critical for large, automated computational projects such as this one, given the overall close correspondence that we found between the two datasets.

The Australian TC season spans calendar years and the first year identifies the season (e.g., 1970/71 is referred to as the 1970 season), and all TCs that entered the NWAUS TC basin are included. There are many TC metrics that can be used in describing the year-to-year variation of TCs. Here, a comprehensive set of 13 TC metrics was chosen for the NWAUS region. They are TC numbers; intense TC (ITC) numbers; TC days; intense TC days (ITCDs); landfalling TCs; intense landfalling TCs; ACE; PDI; mean storm duration (MSD); intense mean storm duration (IMSD); season start date; season end date; and season length, where intense TCs and TC days are defined as having minimum central pressures $<970 \mathrm{hPa}$ (Tables 1 and 2). The accumulated 
TABLE 1. Summary of TC metrics for the NWAUS region 1970 2008. The numbered columns represent yearly counts of 1) tropical cyclones, 2) intense tropical cyclones, 3) TC days, 4) the number of ITC days, 5) TCs making landfall along the NWAUS coast, and 6) ITCs making landfall along the NWAUS coast. An ITC is defined when the minimum pressure of a TC is less than $970 \mathrm{hPa}$.

\begin{tabular}{|c|c|c|c|c|c|c|}
\hline Season & $\begin{array}{c}\mathrm{TC} \\
1\end{array}$ & $\begin{array}{c}\text { ITC } \\
2\end{array}$ & $\begin{array}{c}\text { TCD } \\
3\end{array}$ & $\begin{array}{c}\text { ITCD } \\
4\end{array}$ & $\begin{array}{c}\text { LTC } \\
5\end{array}$ & $\begin{array}{c}\text { ILTC } \\
6\end{array}$ \\
\hline 1970 & 5 & 2 & 37.75 & 3 & 5 & 1 \\
\hline 1971 & 6 & 3 & 40.75 & 9.75 & 1 & 0 \\
\hline 1972 & 8 & 5 & 61.75 & 10.5 & 3 & 2 \\
\hline 1973 & 8 & 4 & 73 & 6.5 & 4 & 2 \\
\hline 1974 & 11 & 3 & 76 & 10.25 & 4 & 1 \\
\hline 1975 & 6 & 3 & 48.75 & 12.5 & 2 & 2 \\
\hline 1976 & 4 & 2 & 24.5 & 2.25 & 2 & 1 \\
\hline 1977 & 4 & 3 & 35.5 & 12.5 & 1 & 1 \\
\hline 1978 & 2 & 1 & 13 & 3.5 & 1 & 1 \\
\hline 1979 & 6 & 5 & 51.5 & 16.25 & 3 & 3 \\
\hline 1980 & 7 & 4 & 63 & 15 & 1 & 1 \\
\hline 1981 & 9 & 2 & 68.25 & 4.75 & 6 & 0 \\
\hline 1982 & 4 & 2 & 31.25 & 3.25 & 3 & 1 \\
\hline 1983 & 8 & 4 & 45.25 & 7.5 & 3 & 2 \\
\hline 1984 & 10 & 6 & 102.25 & 14.25 & 5 & 1 \\
\hline 1985 & 8 & 2 & 50 & 4.5 & 1 & 0 \\
\hline 1986 & 4 & 2 & 32.25 & 3.25 & 2 & 2 \\
\hline 1987 & 1 & 1 & 6.25 & 2 & 0 & 0 \\
\hline 1988 & 4 & 4 & 31 & 9.75 & 3 & 2 \\
\hline 1989 & 5 & 3 & 43.25 & 6.25 & 1 & 0 \\
\hline 1990 & 5 & 1 & 36.5 & 3.5 & 1 & 0 \\
\hline 1991 & 2 & 2 & 15.25 & 6 & 1 & 0 \\
\hline 1992 & 2 & 0 & 17.5 & 0 & 0 & 0 \\
\hline 1993 & 7 & 4 & 55.25 & 9 & 1 & 0 \\
\hline 1994 & 3 & 3 & 24 & 8.25 & 3 & 2 \\
\hline 1995 & 7 & 5 & 59.25 & 11.25 & 4 & 3 \\
\hline 1996 & 5 & 2 & 35.75 & 2.75 & 1 & 1 \\
\hline 1997 & 5 & 3 & 40.25 & 5 & 3 & 1 \\
\hline 1998 & 7 & 7 & 49 & 18.25 & 5 & 1 \\
\hline 1999 & 9 & 6 & 75.75 & 13.25 & 4 & 2 \\
\hline 2000 & 5 & 2 & 36.75 & 6 & 2 & 1 \\
\hline 2001 & 3 & 1 & 16 & 2.5 & 1 & 1 \\
\hline 2002 & 6 & 2 & 43 & 7.75 & 3 & 0 \\
\hline 2003 & 5 & 4 & 38.5 & 13.75 & 3 & 3 \\
\hline 2004 & 4 & 1 & 20.25 & 3.5 & 2 & 1 \\
\hline 2005 & 7 & 4 & 44.75 & 8.25 & 5 & 1 \\
\hline 2006 & 3 & 3 & 25.5 & 7.25 & 3 & 2 \\
\hline 2007 & 5 & 3 & 35.25 & 8 & 1 & 0 \\
\hline 2008 & 7 & 2 & 49.5 & 5.5 & 2 & 1 \\
\hline Mean & 5.6 & 2.97 & 42.39 & 7.62 & 2.46 & 1.10 \\
\hline Std dev & 2.33 & 1.56 & 20.02 & 4.47 & 1.54 & 0.91 \\
\hline
\end{tabular}

cyclone energy and power dissipation index are calculated from maximum sustained winds, determined from current intensity (CI) estimates fitted to a Dvorak (1984) table using

$$
V_{\max }=5.37 \mathrm{CI}^{1.34} \text {. }
$$

The ACE is defined as
TABLE 2. As in Table 1 but for 1) accumulated cyclone energy, 2) power dissipation index, 3) mean storm duration, 4) intense mean storm duration, 5) Julian season start date, 6) Julian season end date, and 7) season length (days).

\begin{tabular}{lcccccrr}
\hline \hline & ACE & PDI & MSD & IMSD & JSD & JED & SL \\
Season & 1 & 2 & 3 & 4 & 5 & 6 & 7 \\
\hline 1970 & 4.97 & 4.14 & 7.55 & 1.5 & 331 & 88 & 122 \\
1971 & 7.63 & 9.07 & 6.79 & 3.25 & 336 & 88 & 117 \\
1972 & 11.29 & 11.76 & 7.72 & 2.1 & 373 & 120 & 112 \\
1973 & 11.49 & 10.28 & 9.12 & 1.62 & 321 & 84 & 128 \\
1974 & 15.31 & 17.47 & 6.91 & 3.42 & 301 & 145 & 209 \\
1975 & 13.19 & 17.77 & 8.12 & 4.17 & 334 & 76 & 107 \\
1976 & 4.34 & 4.1 & 6.12 & 1.12 & 371 & 123 & 117 \\
1977 & 8.99 & 11.94 & 8.88 & 4.17 & 375 & 104 & 94 \\
1978 & 0.45 & 0.26 & 6.5 & 3.5 & 407 & 73 & 31 \\
1979 & 12.82 & 16.92 & 8.58 & 3.25 & 369 & 88 & 84 \\
1980 & 14.94 & 18.39 & 9 & 3.75 & 346 & 77 & 96 \\
1981 & 6.07 & 3.8 & 7.58 & 2.38 & 334 & 66 & 97 \\
1982 & 4.98 & 4.83 & 7.81 & 1.62 & 367 & 119 & 117 \\
1983 & 8.17 & 8.49 & 5.66 & 1.88 & 330 & 63 & 98 \\
1984 & 13.67 & 12.7 & 10.22 & 2.38 & 337 & 114 & 142 \\
1985 & 8.76 & 8.84 & 6.25 & 2.25 & 329 & 99 & 135 \\
1986 & 3.88 & 3.77 & 8.06 & 1.62 & 380 & 107 & 92 \\
1987 & 2.02 & 2.52 & 6.25 & 2 & 402 & 43 & 6 \\
1988 & 6.49 & 7.57 & 7.75 & 2.44 & 346 & 114 & 133 \\
1989 & 4.71 & 4 & 5.65 & 2.08 & 369 & 85 & 81 \\
1990 & 5.47 & 5.82 & 7.3 & 3.5 & 342 & 110 & 133 \\
1991 & 3.18 & 4.61 & 7.62 & 3 & 422 & 103 & 46 \\
1992 & 0.94 & 0.57 & 8.75 & 0 & 389 & 103 & 79 \\
1993 & 8.9 & 9.88 & 7.89 & 2.25 & 349 & 102 & 118 \\
1994 & 5.28 & 7.08 & 8 & 2.75 & 346 & 98 & 117 \\
1995 & 8.18 & 8.14 & 8.46 & 2.25 & 335 & 102 & 132 \\
1996 & 3.66 & 2.74 & 7.15 & 1.38 & 343 & 137 & 159 \\
1997 & 5.38 & 6.07 & 8.05 & 1.67 & 358 & 48 & 55 \\
1998 & 16.15 & 24.1 & 7 & 2.61 & 334 & 98 & 129 \\
1999 & 16.18 & 18.93 & 8.42 & 2.21 & 342 & 110 & 133 \\
2000 & 6.05 & 7.4 & 7.35 & 3 & 335 & 115 & 145 \\
2001 & 2.68 & 3.96 & 5.33 & 2.5 & 323 & 105 & 147 \\
2002 & 5.57 & 5.56 & 7.17 & 3.88 & 386 & 98 & 77 \\
2003 & 10.98 & 13.26 & 7.7 & 3.44 & 350 & 87 & 102 \\
2004 & 3.7 & 5.03 & 50.6 & 3.5 & 364 & 73 & 74 \\
2005 & 8.36 & 10.16 & 6.39 & 2.06 & 368 & 117 & 114 \\
2006 & 4.91 & 5.98 & 8.5 & 2.42 & 429 & 89 & 25 \\
2007 & 8.05 & 8.98 & 7.05 & 2.67 & 360 & 114 & 119 \\
2008 & 9.21 & 10.33 & 7.07 & 2.75 & 323 & 119 & 161 \\
Mean & 7.62 & 8.65 & 7.53 & 2.52 & 355.25 & 97.5 & 107.25 \\
Std dev & 4.25 & 5.52 & 1.10 & 0.90 & 28.5 & 22.0 & 39.5 \\
\hline & & & & & & &
\end{tabular}

$$
\mathrm{ACE}=10^{-4} \sum V_{\max }^{2}
$$

where $V_{\max }$ is the 10-min maximum sustained wind speed (Bell et al. 2000) and is accumulated over the season to give an estimate of the total length and strength of a given TC season. The PDI is defined as

$$
\mathrm{PDI}=\int_{0}^{\tau} V_{\max }^{3} d t \approx \sum_{i=1}^{\tau}\left(v_{\max _{i}}^{3} \Delta t\right)
$$

where $V_{\max }$ is the 10-min maximum sustained wind speed for a given time, $t$ is time, and $\tau$ is the lifetime of 
a given storm: (3) is calculated using the left endpoint approximation with a 6-h time step. The PDI is summed over all TCs to obtain the seasonal value. Last, the mean duration of storms is the number of TCs divided by the number of storms in a given year and start and end dates of seasons are Julian dates.

\section{b. Sea surface temperature data}

The global sea surface temperature data used in this study were obtained from the National Oceanic and Atmospheric Administration extended reconstructed SST (ERSST) dataset (Smith and Reynolds 2004) for January 1970-December 2008. This dataset was constructed from the International Comprehensive Ocean-Atmosphere Data Set (ICOADS). Data is available for monthly SST values on a $2^{\circ} \times 2^{\circ}$ grid from January 1854 .

\section{c. Global modes}

Many global teleconnections are monitored by the NOAA/Climate Prediction Center (CPC). These modes, especially ENSO, are commonly used to predict seasonal TC activity. Most global modes were obtained from the CPC including the Niño-3.4 SST box $\left(5^{\circ} \mathrm{N}-5^{\circ} \mathrm{S}, 170\right.$ $\left.120^{\circ} \mathrm{W}\right)$, Niño-4 SST box $\left(5^{\circ} \mathrm{N}-5^{\circ} \mathrm{S}, 160^{\circ} \mathrm{E}-150^{\circ} \mathrm{W}\right)$, Southern Oscillation index (SOI), Northern Oscillation index (NOI) (Schwing et al. 2002), North Atlantic Oscillation (NAO) (Walker and Bliss 1932), Pacific-North American (PNA) pattern (Wallace and Gutzler 1981), Pacific decadal oscillation (PDO) (Walker and Bliss 1932; Zhang et al. 1997; Mantua et al. 1997), Arctic Oscillation (AO) (Thompson and Wallace 1998; Higgins et al. 2000), and QBO. The Indian Ocean dipole (IOD) was calculated from the NOAA ERSST dataset and is based on the dipole discussed by Saji et al. (1999). Only interseasonal parameters are investigated here, so the Madden-Julian oscillation is not used.

\section{d. Atmospheric data}

Monthly values of geopotential height, air temperature, sea level pressure, and $u$ and $v$ wind components are from the National Centers for Environmental PredictionNational Center for Atmospheric Research (NCEPNCAR) reanalysis dataset (Kalnay et al. 1996), with a horizontal grid spacing of $2.5^{\circ}$. Except for the mean sea level pressure, data were obtained for 17 vertical levels: 1000,925 , $850,700,600,500,400,300,250,200,120,100,70,50,30,20$, and $10 \mathrm{hPa}$. The variables in this study are class A variables; that is, they are strongly influenced by observational data and are considered the most reliable (Kalnay et al. 1996).

\section{e. Correlation analysis}

The time series of the global modes (discussed above) were correlated with NWAUS basin TC frequency time series using the Pearson product-moment correlation. The Pearson correlation is

$$
r_{x y}=\frac{\frac{1}{n} \sum_{i=1}^{n}\left[\left(x_{i}-\bar{x}\right)\left(y_{i}-\bar{y}\right)\right]}{\left[\frac{1}{n-1} \sum_{i=1}^{n}\left(x_{i}-\bar{x}\right)^{2}\right]^{1 / 2}\left[\frac{1}{n-1} \sum_{i=1}^{n}\left(y_{i}-\bar{y}\right)^{2}\right]^{1 / 2}},
$$

with the usual mathematical conventions applying to the notation (Wilks 2005). Each known global mode was grouped into 3-month bins starting with the JanuaryMarch bin preceding the onset of the TC season, through to June-August, following the TC season, for 1970-2008. Correlation analyses between the frequency of TCs in the NWAUS TC basin and the monthly anomaly values of SST, geopotential height, air temperature, mean sea level pressure, and the $u$ and $v$ components of the wind in 3-month bins beginning January-March (preceding the TC season) through September-November (start of the TC season) were made over the entire observational domain. Anomalies are relative to the long-term mean from 1970 to 2008.

To determine the significance of a correlation between a TC metric and any variable the two-sided $t$ test is used. For 34 degrees of freedom, the two-sided $t$ value is 1.6909 for the $90 \%$ confidence interval (Wilks 2005). Neither the all-TC trend $(t=1.026)$ nor the intense-TC trend $(t=0.058)$ is significant, and the TC time series has a serial correlation of +0.32 , which is accounted for when computing the $t$ values for each confidence interval.

\section{f. Composite analysis}

Composite analyses were generated for geopotential height and sea level pressure anomaly fields by averaging the 10 most active and inactive years. The longterm means from the NCEP-NCAR reanalysis dataset are based on 1968-96 values of each field and anomalies are relative to that long-term mean. Owing to ties in various years, the most active years totaled 13 and were 1974, 1984, 1999, 1981, 1972, 1973, 1983, 1985, 2008, 1980, 1993, 1995, and 1998 (Table 3). The least active years were 1987, 1991, 1992, 1978, 1994, 2001, 1976, 1977, 1982, and 1988 (Table 3). For each set of $10 \mathrm{yr}$, the individual seasons were averaged and the mean subtracted from the long-term mean to produce composite maps.

\section{Results}

\section{a. TC metrics}

The NWAUS TC basin averaged 5.6 TCs per year during the $39-\mathrm{yr}$ period from the 1970 to $2008 \mathrm{TC}$ seasons 
TABLE 3. The 13 most active and 10 least active seasons in terms of TC frequency for the NWAUS region.

\begin{tabular}{lcccc}
\hline \hline \multirow{2}{*}{ Active TC seasons } & & \multicolumn{2}{c}{ Inactive TC seasons } \\
Year & TCs & & Year & TCs \\
\hline 1974 & 11 & 1987 & 1 \\
1984 & 10 & 1991 & 2 \\
1999 & 9 & 1992 & 2 \\
1981 & 9 & 1978 & 2 \\
1972 & 8 & 1994 & 3 \\
1973 & 8 & 2001 & 3 \\
1983 & 8 & 1976 & 3 \\
1985 & 8 & 1977 & 4 \\
2008 & 8 & 1982 & 4 \\
1980 & 7 & 1988 & \\
1993 & 7 & & \\
1995 & 7 & & \\
1998 & 7 & & \\
\hline
\end{tabular}

with a standard deviation of 2.3 TCs (Fig. 2a). There is a small downward linear trend in the annual frequency of all TCs over this period, but it is not significantly different from zero. For intense TCs, with minimum central pressures $<970 \mathrm{hPa}$, there is no discernible linear tread over the same period (Fig. 2a). For the number of TC days and intense TC days, similar trends to TC frequency are apparent (Fig. 2b). Again, neither linear trend is significant at the $90 \%$ confidence level, with $t$ values of 1.31 and 0.247 for TC days and intense TC days, respectively. The average number of TC days in the NWAUS region is 42.4 with a standard deviation of 20.0 days. Of importance to population centers along the northwest Australian coast is the number of landfalling TCs. On average, 2.5 TCs make landfall each year and one is intense. Landfalling TCs exhibit no significant linear trends (Fig. 2c).

The ACE and PDI metrics provide more accurate assessments of the strength of the TC season. Alone, the number of TCs or TC days during a season may not capture the true impact of that season. Year-to-year fluctuations of ACE and PDI are seen in Fig. 2d. However, neither metric exhibits a linear trend significant at the $90 \%$ confidence interval, with $t$ values of 1.011 and 0.492 for ACE and PDI, respectively (Fig. 2d).
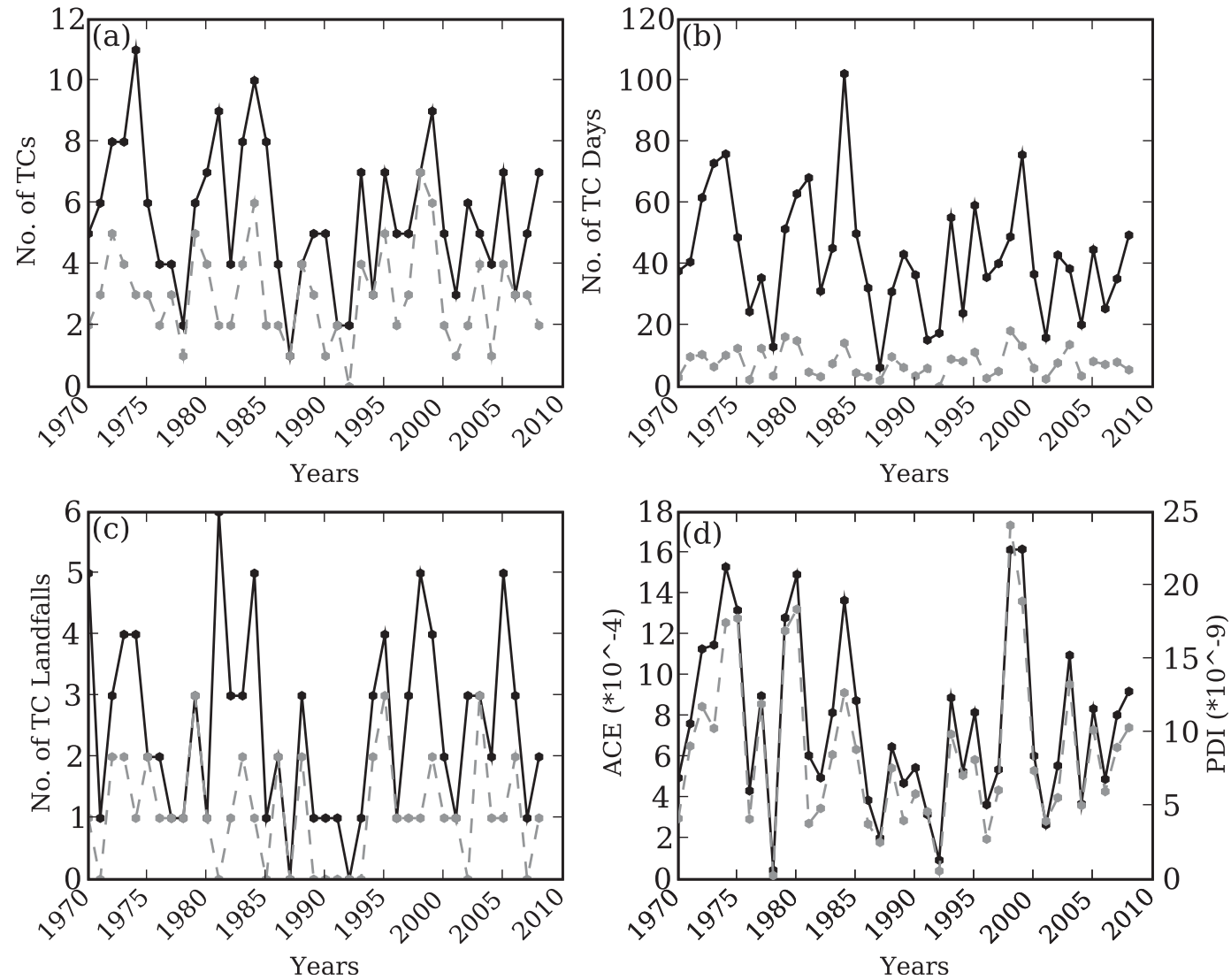

FIG. 2. Time series of the following TC metrics (a) all TCs (solid black) and intense TCs (dashed gray), (b) all TC days (solid black) and intense TC days (dashed gray), (c) landfalling TCs (solid black) and intense landfalling TCs (dashed gray), and (d) ACE (solid black) and PDI (dashed gray), for the NWAUS region $\left(105^{\circ}-135^{\circ} \mathrm{E}\right)$ from 1970 to 2008. 

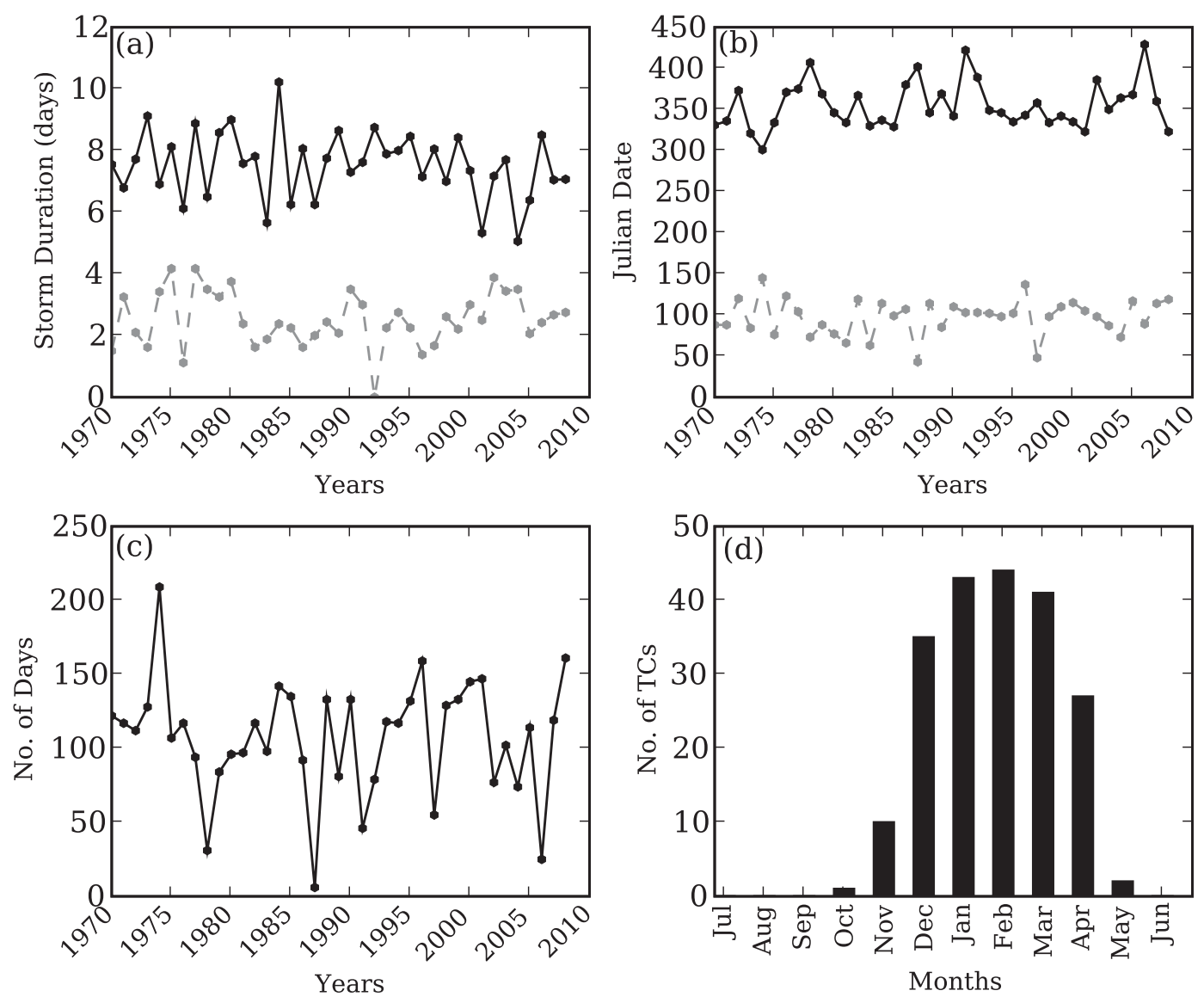

FIG. 3. Time series of the following TC metrics (a) mean storm duration (solid black) and mean intense storm duration (dashed gray), (b) season Julian start date (solid black) and season Julian end date (dashed gray), (c) season length (solid black), and (d) the number of TCs occurring during each month, for the NWAUST region $\left(105^{\circ}-135^{\circ} \mathrm{E}\right)$ from 1970 to 2008 .

The TC dataset reveals that the NWAUS region does not exhibit large year-to-year variations in mean storm duration (Fig. 3a), with the average storm duration 7.5 days and standard deviation 1.1 days. On average, storms in the NWAUS region are at intense strength for only 2.5 days per season with a standard deviation of 1 day. The average date of formation of the first storm is 21 December and the last storm ends on 7 April. Season start dates are slightly more variable than season end dates, with standard deviations of 28.5 and 22 days, respectively (Fig. 3b). The number of TCs that form in a season is highly correlated $(\sim-0.67)$ with the season start date but not with the season end date $(\sim+0.2)$. Average seasonal length is 107.25 days with a standard deviation of 39.5 days (Fig. 3c). The NWAUS region TC season typically runs from November to April (Fig. 3d). TCs can form outside the typical seasonal time frame; however, in the 39-yr record only three TCs-one in October and two in May-formed outside that time period (Fig. 3d).
It has been suggested that an early NWAUS TC season, where a TC is likely to impact the Western Australian region, is one in which the first storm forms before Christmas (B. W. Buckley 2009, personal communication). However, our TC data analysis of season start dates for the 39-yr period in this study reveals that $57.5 \%$ of the seasons began on or before 25 December. Clearly, then, a storm forming in the NWAUS region before Christmas is not early and, therefore, the definition needs to be computed directly from the TC dataset. Conversely, a late-starting NWAUS TC season is suggested to be one in which the first storm does not form until February or later (B. W. Buckley 2009, personal communication). Again, only four seasons on record-1978, 1987, 1991, 2006 - have started as late as 1 February, with all starting after 6 February, so this definition also needs to be computed. The middle $50 \%$ of the season start date ranges from 335 to 370 (1 December-5 January), which is a total of 19 seasons, with 10 seasons in the first and last quartiles. Statistically based early and late start dates 

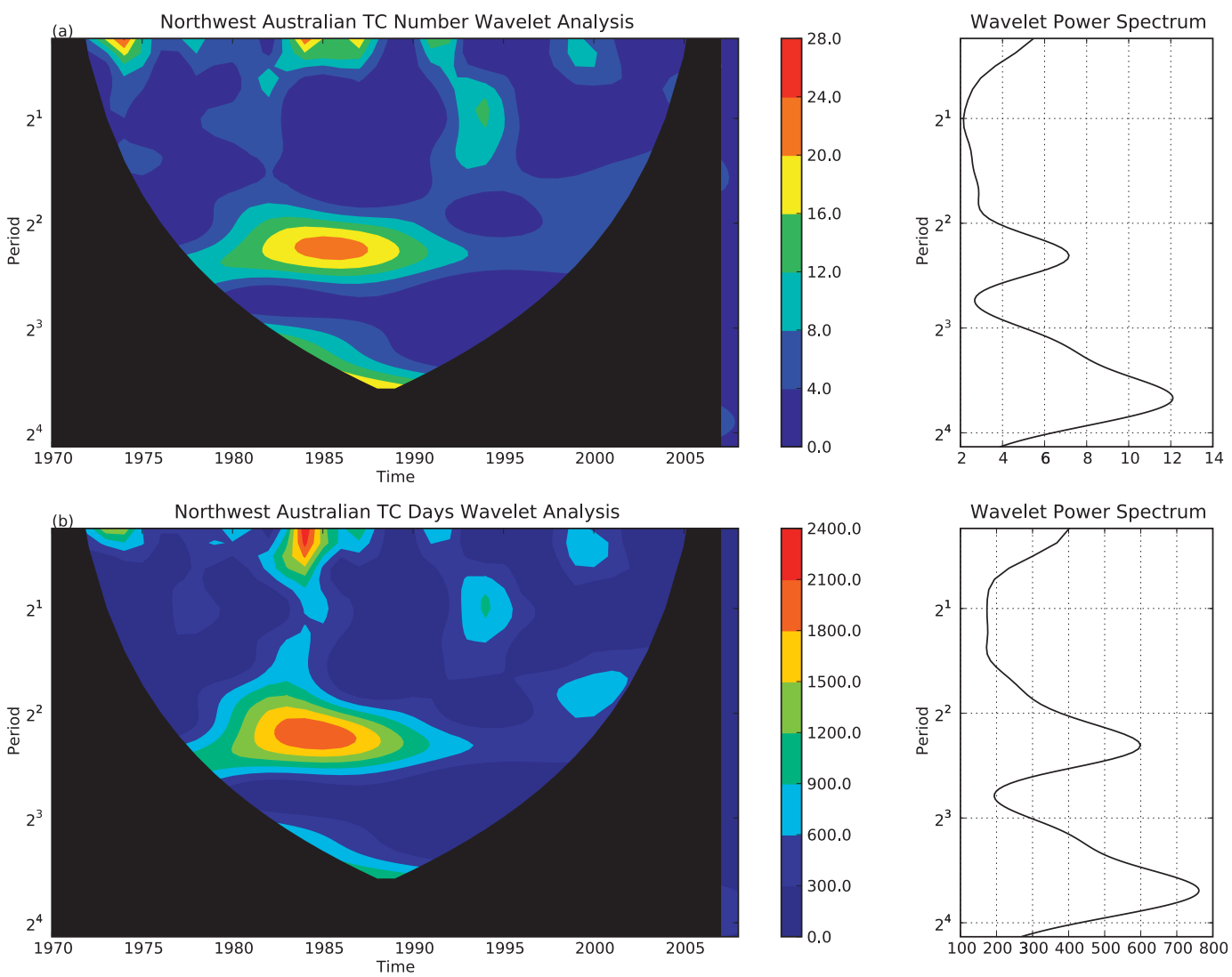

FIG. 4. Wavelet power spectra for (a) all TCs and (b) TC days in the NWAUST region using the Morlet mother wavelet.

are prior to 1 December and after 5 January. With these dates we find that for the NWAUS subbasin, an early starting season increases the likelihood of an aboveaverage number of TCs occurring during that season. Similarly, a late-starting season is likely to have a wellbelow-average number of TCs. An early-starting season also is likely to be longer than one that starts late, and a late-starting season is more likely to be of below-average duration.

No statistically significant linear trends were found in any of the 13 TC metrics discussed above. However, there could be other dominant modes of variability present in the TC time series. To determine if there are other common frequencies within some of the TC metrics, a wavelet analysis was conducted (Torrence and Campo 1998). A Morlet wavelet analysis of the time series of the number of TCs for the NWAUS region identified two major peaks in the wavelet power spectra (Figs. 4a and 5a) at 4-6 and 12-14 yr. With fewer than four decades, the signal could be spurious; however, with the decadal signal appearing in two wavelet power spectrums (Morlet and Mexican Hat), we have more confidence in the signal (Figs. 4 and 5). Given the brevity of the reliable TC record, any multidecadal variability within the NWAUS region cannot be ascertained from a wavelet analysis, and no multidecadal trend can reliably be identified. Similar results hold for a wavelet analysis of TC days (Figs. 4b and 5b), which likely is due to the TC frequency and TC days time series being highly correlated.

\section{b. Seasonal composites}

Composite maps, constructed from NCEP-NCAR reanalysis variables, can be used to identify changes in global atmospheric patterns between active and inactive TC seasons. The composite maps are constructed from the 13 most active seasons and the 10 least active seasons for the entire global domain for various atmospheric parameters. To highlight more effectively the changes between those seasons, anomalies from the long-term means of each field are used. The geopotential height field at 700-hPa yields discernible pattern differences between active and inactive seasons (Figs. 6a and 6c). Other levels follow a similar pattern, with the height differences increasing slightly with decreasing pressure for both active and inactive seasons. Various parts of the globe experience differences in geopotential height anomalies 

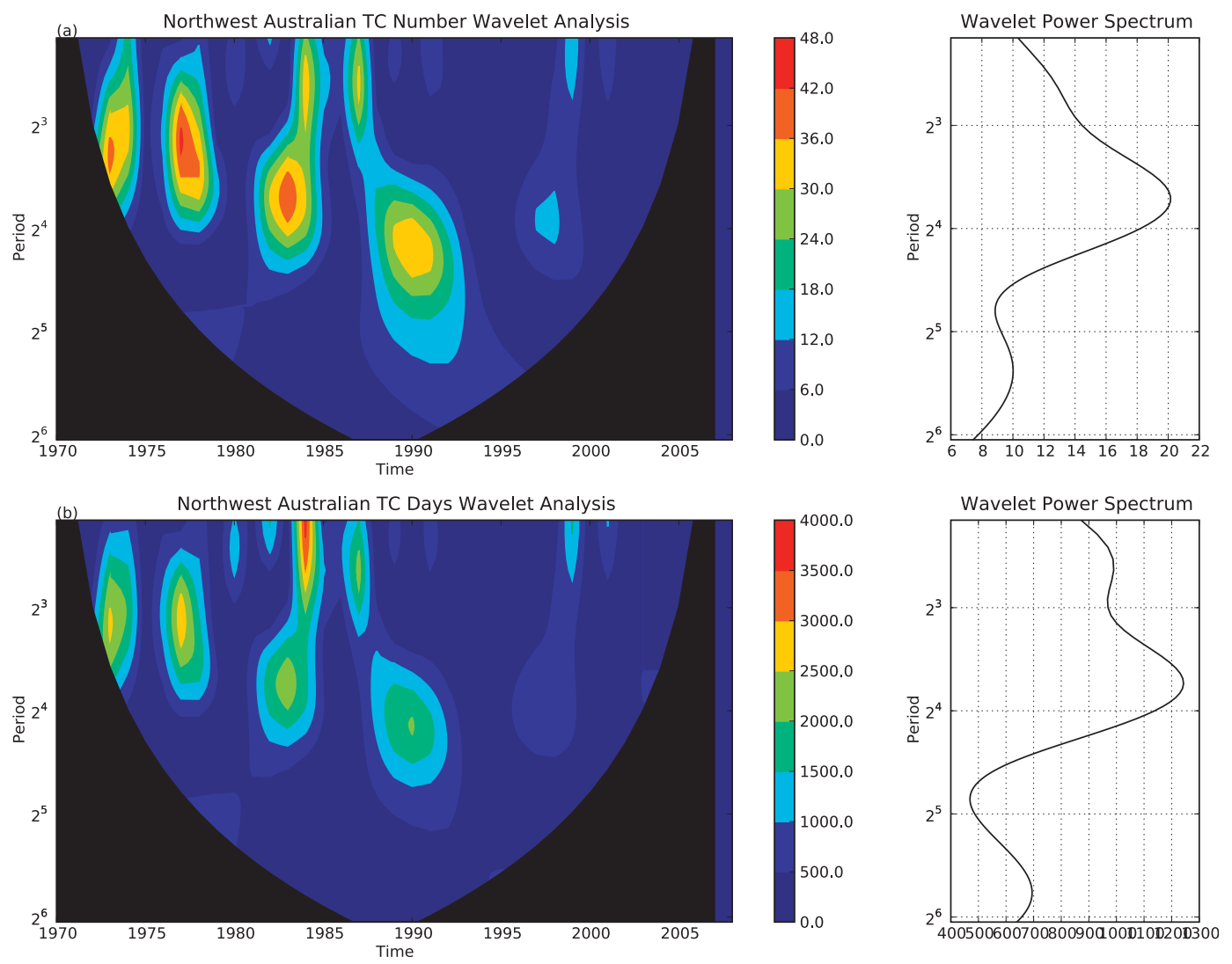

FIG. 5. As in Fig. 4 but for the Mexican Hat mother wavelet.

between active and inactive TC seasons. The Northern Hemispheric polar region has higher geopotential heights during active NWAUS TC seasons (Fig. 6a) and lower geopotential heights during inactive seasons (Fig. 6c). Moreover, geopotential heights are lower during an active NWAUS TC season off the coast of Japan, with higher geopotential heights during inactive seasons.

Previous work has investigated "standard" ENSOrelated SSTs. However, it is informative to investigate global SST anomalies (SSTAs) for other regions to explain the NWAUS TC frequency time series. Composite maps of the 13 most active and 10 least active NWAUS TC season yields an ENSO-like signal for NovemberApril (Figs. 6b and 6d). These composite maps suggest that ENSO-like signals play a role in modulating the activity between active and inactive seasons.

\section{c. Preseason correlations}

\section{1) ENSO INDICES}

There has been considerable research on the relationship between Australian region TCs and various indicators of the mode of the ENSO (e.g., Nicholls 1979, 1985, 1992; Revell and Goulter 1986; Solow and Nicholls 1990;
Evans and Allan 1992; Nicholls et al. 1998; Broadbridge and Hanstrum 1998; Ramsay et al. 2008). Most have found a significant relationship between TC activity and ENSO activity because much of the Australian region is directly impacted by changes in the Walker circulation, which in turn is related to convective activity in the southwestern Pacific Ocean.

In most prediction schemes for the Australian region, ENSO is a major predictor. This section investigates a range of different standard ENSO-related variables to determine if they explain a large portion of the variance of TCs in the NWAUS region. One approach is to use different SST regions. There are four areas of tropical Pacific SSTs commonly used: extreme eastern tropical Pacific SSTs (Niño- $1+2 ; 0^{\circ}-10^{\circ} \mathrm{S}, 90^{\circ}-80^{\circ} \mathrm{W}$ ), eastern tropical Pacific SSTs (Niño-3; $5^{\circ} \mathrm{N}-5^{\circ} \mathrm{S}, 150^{\circ}-90^{\circ} \mathrm{W}$ ), central tropical Pacific SSTs (Niño- $4 ; 5^{\circ} \mathrm{N}-5^{\circ} \mathrm{S}, 160^{\circ} \mathrm{E}-150^{\circ} \mathrm{W}$ ), and east-central tropical Pacific SSTs (Niño-3.4, which is a combination of the Niño- 3 and Niño- 4 SSTs; $5^{\circ} \mathrm{N}-5^{\circ} \mathrm{S}$, $\left.170^{\circ}-120^{\circ} \mathrm{W}\right)$. Often the SSTs are reported as anomalies (SSTAs), defined as the difference between the current period and a long-term mean (typically $30 \mathrm{yr}$ ). Here, the Niño-3.4 and Niño-4 areas are used, with anomalies relative to 1971-2000 means. When a large positive (negative) 

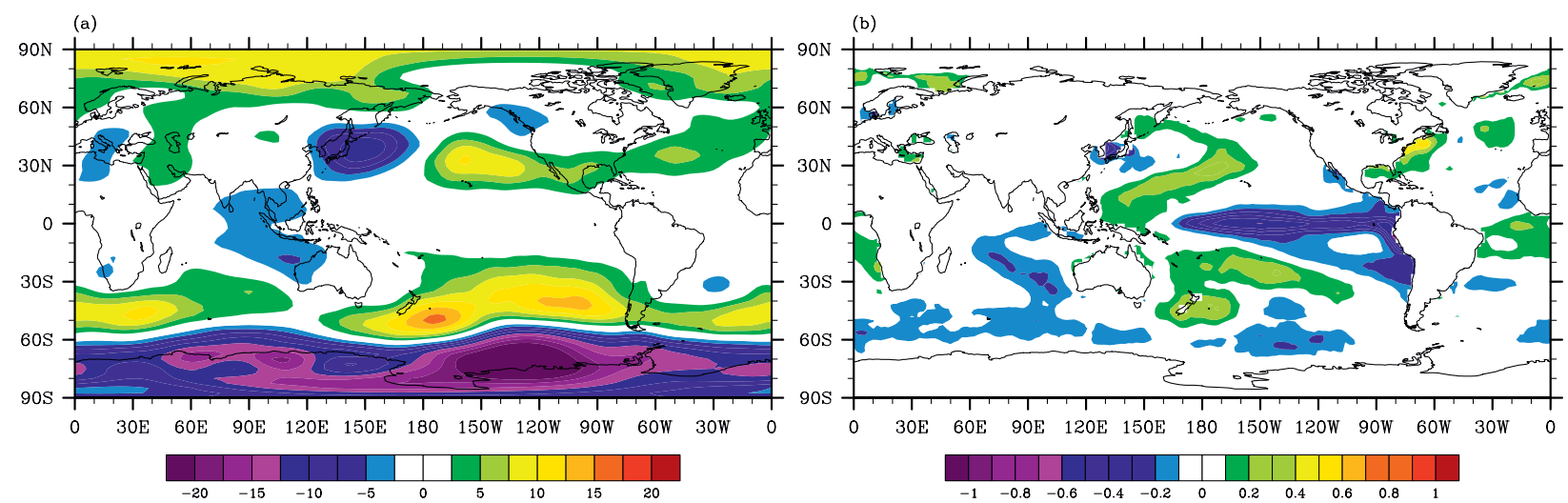

(c)

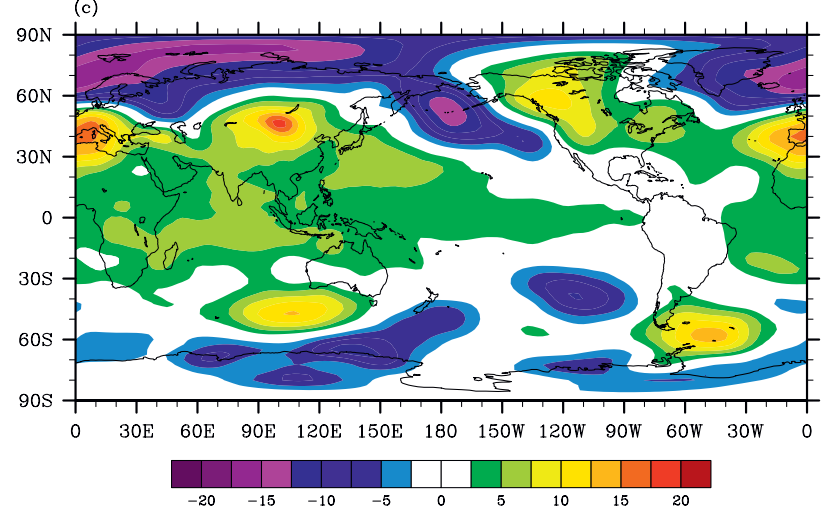

(d)

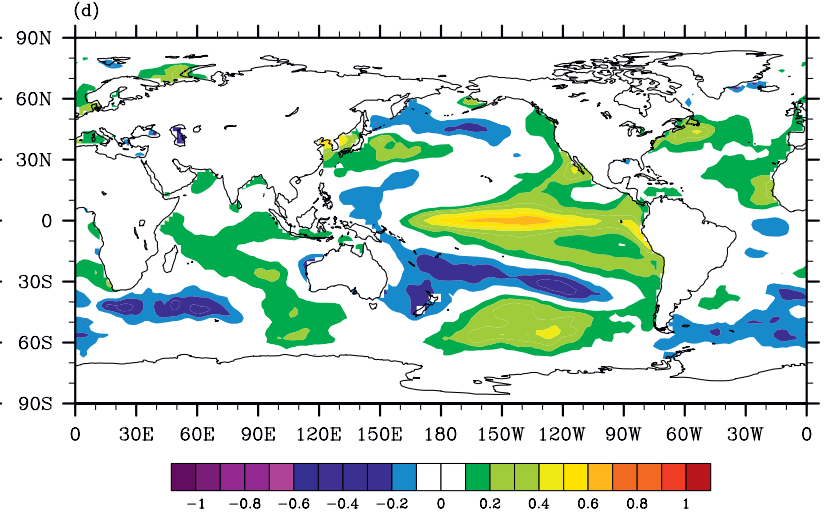

FIG. 6. November-April composite of 700-hPa geopotential height for (a) most active and (c) least active TC frequency seasons; November-April composite of SSTAs for (b) most active and (d) least active TC frequency seasons.

SSTA occurs in either Niño-3.4 or Niño-4, it is associated with an El Niño (La Niña) event as SSTs in those regions increase above (decrease below) the long-term mean. A temperature anomaly greater than $0.5^{\circ} \mathrm{C}\left(-0.5^{\circ} \mathrm{C}\right)$ in the Niño-3.4 region indicates likely El Niño (La Niña) conditions.

The frequency of TCs in the NWAUS basin is not highly correlated with Niño SSTs prior to the start or during the TC season, for the period 1970-2005 (Fig. 7a). A two-sided $t$ test (Wilks 2005) for significance must take into account the serial (lag 1) correlation of the TC time series (Bretherton et al. 1999). A correlation magnitude of $0.46(0.57)$ or greater is significant at the $95 \%$ ( $99 \%)$ confidence interval under standard normality assumptions for the 36-yr TC dataset. The standard ENSO parameter with the highest correlation is the Niño-4 SSTAs. Prior to the beginning of the TC season, correlations peaked during June-August and July-September $(-0.47)$. During the season the Niño-4 SSTAs reached a maximum correlation during March-May (-0.51). Another standard ENSO SST region, Niño-3.4, initially was less highly correlated with NWAUS TC frequency but increased substantially during the season, peaking at -0.48 during February-April and March-May, that is, at the same time as the Niño-4 SSTAs. These correlations are substantially lower than those of Ramsay et al. (2008) for the entire Australian region but are still significant at the 95\% confidence interval. Ramsay et al. (2008) found statistically significant correlations for both the Niño-3.4 SSTAs and Niño-4 SSTAs.

The correlations between Niño-3.4 and Niño-4 SSTAs and seasonal TC days revealed similar values to the correlations for TC counts (Fig. 7b). The largest correlations $(-0.5)$ occur during the NWAUS TC season. Prior to the beginning of the TC season, Niño-4 SSTAs approach significance levels of $95 \%$ by the June-August 3 -month bin and maintain that level through the TC season. The Niño-3.4 SSTAs are not significant until after the TC season begins, during the January-March 3-month bin. In the February-April time frame, Niño-3.4 and Niño-4 SSTAs have approximately the same correlation values $(-0.5)$ for two 3-month bins and then diverge after the end of the TC season (Fig. 7b).

Another parameter used to identify the ENSO mode is the SOI. For the NWAUS region, again there is a substantially lower correlation between TC activity and SOI than reported for the entire Australian basin by Ramsay et al. (2008) (Fig. 7a). The SOI correlation initially peaked 
(a)

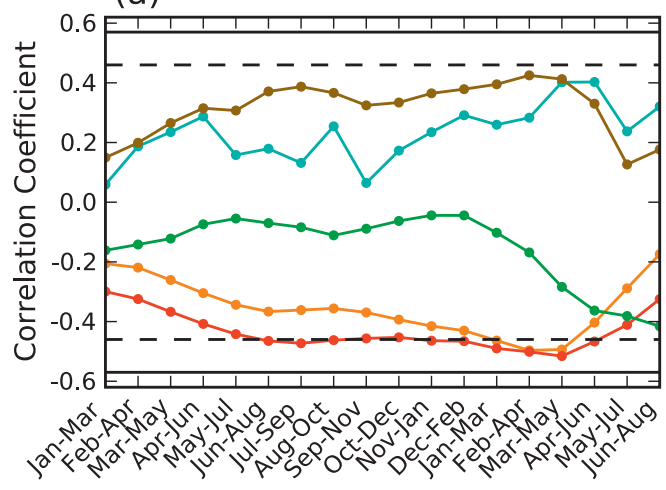

(c)

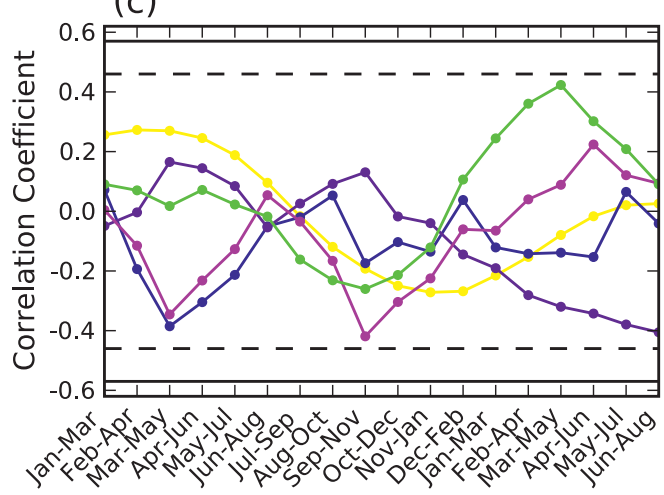

3-Month Bins (b)

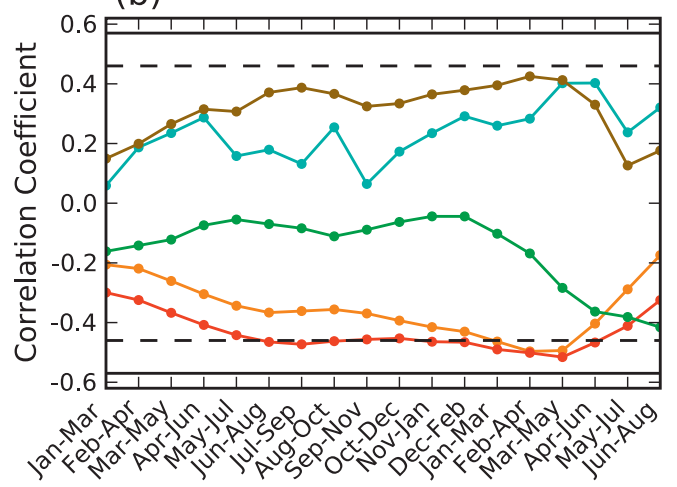

(d)

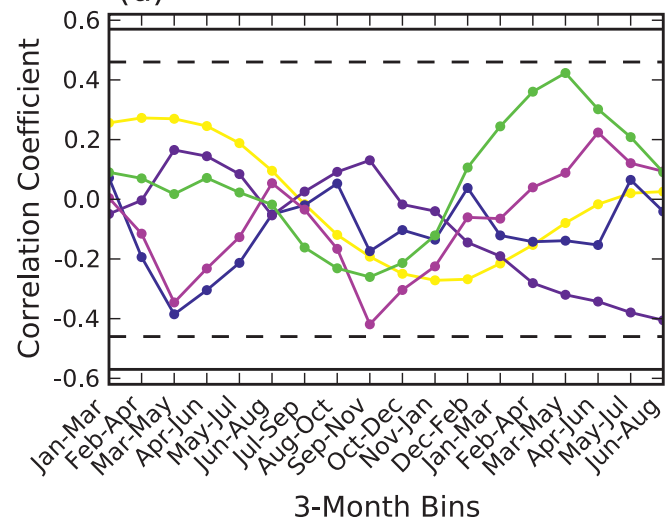

FIG. 7. Correlations between (a) ENSO-related parameters Niño-3.4 (orange), Niño-4 (red), SOI (brown), PDO (green), and NOI (cyan) and the number of TC frequency. (b) As in (a) but for TC days. (c) As in (a) but for QBO (yellow), NAO (blue), PNA pattern (light green), AO (magenta), and the IOD (dark purple). (d) As in (c) but for TC days. Each correlation begins with the 3-month bin January-March prior to the beginning of the NWAUS TC season through the June-August 3-month bin following the end of the NWAUS TC season. The 95\% (99\%) confidence intervals are plotted in dashed (solid) black lines.

during July-September $(+0.38)$ before the season began and peaked a second time during the season in FebruaryApril $(+0.39)$; both are not statistically significant at the $95 \%$ level. Ramsay et al. found correlations for SOI statistically significant at the $99 \%$ confidence interval for TCs in the entire Australian region. The lower correlation values for the NWAUS region alone may be attributable to the exclusion of southwest Pacific TCs in this study. Similar correlations are found between SOI and TC days (Fig. 7b). At no time prior to the beginning of the TC season are the correlations significant. Correlations increase as the TC season approaches, reaching a maximum value of +0.42 at the season's end in MarchMay, so SOI is not a useful predictor for TC days.

The NOI is an analog climate index to SOI and is intended to assess more accurately the tropical-extratropical Pacific Ocean interactions resulting from El Niño and La Niña episodes. An important feature of this index is its ability to determine not only changes in the Walker circulation (like the SOI) but also changes in the Hadley circulation, which affects the meridional transport of momentum, energy, and mass between the tropics and extratropics (Schwing et al. 2002). The NOI also highlights cross-equatorial teleconnections in the Pacific Ocean. Correlations between the NOI and NWAUS TCs follow similar trends to the SOI, with a preseason peak in April-June $(+0.30)$ and a postseason peak $(+0.41)$ in March-May and April-June (Fig. 7a). The NOI and SOI are highly correlated $(+0.72)$ across all 3-month bins in this study. The larger correlation after the season suggests that the tropics have a greater impact on the extratropics. The correlations between the number of TC days and the NOI yield similar values to those for TC numbers (Fig. 7b). Correlations prior to the beginning of the TC season generally are less than +0.20 , increasing during the season to a maximum of +0.35 during the March-May 3-month bin. Therefore, the NOI, like the SOI, is not a strong candidate for inclusion in 
a seasonal prediction scheme for TC frequency or TC days.

Initially discovered by Walker and Bliss (1932), the PDO is an analogous oscillation to the NAO. The PDO is defined as a seesaw in north-south Pacific sea level pressure and is the leading eigenvector in a principal component analysis of monthly SST anomalies poleward of $20^{\circ} \mathrm{N}$ between $110^{\circ} \mathrm{E}$ and $110^{\circ} \mathrm{W}$ (Mantua et al. 1997). This oscillation varies on interannual to decadal time scales, describes decadal variations in the Northern Hemisphere, and can modulate ENSO teleconnections.

A positive $\mathrm{PDO}$ is indicated by a deeper Aleutian low and the mean extratropical storm track is pushed southward. When the positive phase of the PDO is in concert with an El Niño event, more moisture is available to storms moving across the Pacific, altering precipitation patterns in the western Pacific Ocean. Conversely, during the negative (cool phase) of the PDO, the Aleutian low is weaker and extratropical storms track farther north. When coupled with a La Niña phase, precipitation is enhanced in the U. S. Northwest and British Columbia, while in the southwestern United States, precipitation is decreased (Gershunov and Barnett 1998; Goodrich 2007).

The interannual variability of the PDO does not correlate significantly with the NWAUS TC frequency before the beginning of the season, but does reach a peak in June-August after the TC season $(-0.41$, Fig. $7 a)$. Correlations between the PDO and the number of TC days are similar to those with the number of TCs, with the maximum occurring after the end of the TC season during the June-August 3-month bin after the season has ended (Fig. 7b). As with the NOI, the stronger correlations following the NWAUS TC season may reflect the influence of the tropical Pacific Ocean on Northern Hemispheric patterns during the late spring/early summer. The PDO has mainly been used for decadal oscillations, and the 39-yr period here precludes certainty of multidecadal trends. Future studies may find more substantial connections to NWAUS TC frequency, when multidecadal signals can be identified and researched more deeply.

There are a few periods where the traditional ENSO parameters (Niño-3.4, Niño-4, and SOI) are statistically significant, but typical correlations are substantially less than those for TC activity over the entire Australian region. The NOI and PDO, while important in describing interannual to decadal variations in the Pacific Ocean region, also appear to have little modulating effect on NWAUS TCs. This diminished role of traditional ENSO parameters for the NWAUS basin is in contrast to recent results by Ramsay et al. (2008), which found highly statistically significant relationships between the TC frequency for the entire Australian basin and the traditional
ENSO parameters. Results of this study therefore confirm and extend earlier findings by Broadbridge and Hanstrum (1998) that the correlation of SOI to TC numbers was substantially less in the NWAUS region when compared to the correlations for the entire basin. These findings do not imply that ENSO does not play a role in the variability of TC frequency or TC days in the NWAUS region, only that its role is less statistically significant than for the whole Australian basin.

\section{2) NON-ENSO INDICES}

A difficulty with using global modes is that they are generally developed for the Northern Hemisphere. However, they may modulate equatorial convergence patterns, with consequential impact on TCs in the Australian region. In addition to traditional global modes - the NAO, the $\mathrm{AO}$, the PNA pattern, and the QBO-we include the IOD for its NWAUS location.

Two primarily Northern Hemispheric patterns are the NAO and the AO, which have been linked to the variability of temperature and precipitation over North America and Europe. The NAO has been defined in several different ways, but refers to a north-south dipole in SLP in the North Atlantic Ocean (e.g., Walker and Bliss 1932; Wallace and Gutzler 1981; Hurrell 1995; Ambaum et al. 2001). The NAO also appeared in the analysis by Barnston and Livezey (1987) as one of the 10 leading rotated principal components of Northern Hemispheric $500-\mathrm{hPa}$ geopotentials. The NAO was linked to global TC activity by Elsner and Kocher (2000) over the period 1966-97. Frank and Young (2007) found similar results, especially when a positive NAO phase coupled with a positive ENSO (El Niño) phase during which an increase occurs in TC activity, except for the North Atlantic which has long been known to have decreased TC activity during positive ENSO phases. This trend is seen in other TC metrics, including storm days and TCs that reach hurricane strength.

Closely related to the NAO is the AO, and their correlation exceeds +0.8 during one 3 -month bin. Generally, the correlation between the NAO and the AO exceeds +0.5 for most 3 -month bins. The $\mathrm{AO}$ is the leading mode of a principal component analysis of Northern Hemispheric SLP and explains $25 \%$ of the variance (Ambaum et al. 2001). The AO index is calculated by projecting the $1000-\mathrm{hPa}$ height anomalies poleward of $20^{\circ} \mathrm{N}$ on the leading pattern of the AO. The correlation of NWAUS TC frequency with NAO peaks in March-May $(-0.36)$, but drops to zero after June-August (Fig. 7c). The AO correlation peaks in March-May $(-0.34)$ and again in September-November $(-0.43)$, which is almost significant at the $95 \%$ confidence level. However, during the TC season the correlation drops to near zero (Fig. 7c). 
Correlations between NWAUS TC days and NAO index also peak in March-May ( -0.34$)$, but decrease to near zero as the TC season approaches, resembling the pattern between the NAO and TC frequency (Fig. 7d). The correlations between the AO and TC days are similar, with peaks in March-May (-0.34) and SeptemberNovember $(-0.40)$. After the second peak, the correlation is near zero (Fig. 7d).

The PNA is a low-frequency teleconnection pattern in the North Pacific Ocean, similar to the NAO. The calculation of the PNA pattern uses rotated principal component analysis (Barnston and Livezey 1987). A feature of the positive phase of the PNA is belowaverage heights near Hawaii and above-average heights south of the Aleutian Islands, which is a north-south dipole similar to the NAO. The East Asian jet stream shifts eastward during the positive PNA phase and the jet exit region nears the U.S. West Coast. During the negative phase, the East Asian jet moves westward, creating a blocking pattern over the central Pacific, producing a split flow regime across the Pacific (Wallace and Gutzler 1981). Despite the PNA accounting for changes in Northern Hemispheric weather patterns, the PNA can cause a shift in that pattern, which in turn alters the location of the Southern Hemispheric convergence zone. The PNA correlation with the number of TCs is less than magnitude 0.3 until after the TC season, when correlations increase in size to -0.39 in June-August (Fig. 7c). Similarly, the correlation between the PNA and TC days is near zero prior to the NWAUS TC season (Fig. 7d).

The QBO dataset was obtained from the Climate Prediction Center Web site. The QBO was originally used by Gray $(1984 a, b)$ as a seasonal TC predictor for the North Atlantic. Gray reported that, when the QBO is in a westerly phase there, $50 \%-100 \%$ more TCs develop than for an easterly phase, but the nature of the link between TC activity and the QBO remains uncertain (Baldwin et al. 2001). For NWAUS, the correlation between the QBO and TC frequency peaks in March-May $(+0.30)$ and in December-February $(-0.25)$. The correlation magnitude between the QBO and TC days is always $<0.2$ before, during, or after the NWAUS TC season (Fig. 7c), so the QBO explains little NWAUS variability in TC frequency or days (Fig. 7d).

Saji et al. (1999) identified a leading mode of variability in the Indian Ocean: the Indian Ocean dipole. The IOD is the difference in SST anomalies between the tropical western Indian Ocean $\left(10^{\circ} \mathrm{S}-10^{\circ} \mathrm{N}, 50^{\circ}-70^{\circ} \mathrm{E}\right)$ and the tropical southeastern Indian Ocean $\left(10^{\circ} \mathrm{S}-0^{\circ}, 90^{\circ}-110^{\circ} \mathrm{E}\right)$. The IOD peaks in September-November $(-0.29)$ just prior to the TC season and again after the season, in March-May (+0.43). Similar correlations exist for the IOD and TC days with the largest after the season, during March-May (+0.45, Fig. 7d). Although independent of the ENSO phase (Saji et al. 1999), the IOD does not explain a significant level of variability in TC frequency or days in the NWAUS basin before the season (Figs. 7c and 7d).

Generally, global modes do not correlate highly with TC frequency or TC days in the NWAUS basin. This possibly is due to the global modes having been identified for Northern Hemispheric patterns. However, previous literature on global teleconnections indicates that patterns in one hemisphere can impact TC development in the opposite hemisphere (Love 1985). Thus, despite their importance in quantifying the effect of known global modes on NWAUS TC activity, these modes appear to have little obvious explanatory value.

\section{3) NCEP-NCAR REANALYSIS FIELDS}

Correlation maps were compiled from the NCEPNCAR global reanalysis dataset for 3-month bins, beginning in January-March and ending in SeptemberNovember. Several correlation maps yielded areas of strong correlation with TC frequency. The $850-\mathrm{hPa}$ geopotential heights for May-July are highly correlated $(>+0.5$, Fig. 8a) with NWAUS TC frequency over the south Indian Ocean (SIND850; 42.5-55 $\left.\mathrm{S}, 47.5-72.5^{\circ} \mathrm{E}\right)$. Before active (inactive) TC seasons anomalously higher (lower) heights exist over the south Indian Ocean. Central North American (NA700; 37.5 $-47.5^{\circ} \mathrm{N}, 102.5^{\circ}-82.5^{\circ} \mathrm{W}$ ) April-June $700-\mathrm{hPa}$ geopotential heights are significantly correlated with TC frequency in the NWAUS region ( -0.64 , Fig. 8b). The May-July $850-\mathrm{hPa}$ air temperatures over the central North Pacific (HI850; $10^{\circ}-20^{\circ} \mathrm{N}$, $\left.155^{\circ}-132.5^{\circ} \mathrm{W}\right)$ are significantly correlated with NWAUS TC frequency $(-0.63$, Fig. 8c). Both an east-west dipole in the Indian Ocean and a north-south tripole in the central Pacific Ocean are present in the correlation map. The June-August 925-hPa geopotential heights are significantly correlated $(-0.65$, Fig. $8 d)$ with NWAUS TC frequency over the South Atlantic Ocean (SATL925; $\left.17.5^{\circ}-32.5^{\circ} \mathrm{S}, 12.5^{\circ}-0^{\circ} \mathrm{W}\right)$. A second area of high correlation in the eastern Pacific Ocean (EPAC $925 ; 15^{\circ}-27.5^{\circ} \mathrm{N}$, $130^{\circ}-115^{\circ} \mathrm{W}$ ) is not prominent in the composite difference map and its variability is likely related to the variability of ENSO. Additional areas of weak to moderate correlations lie across the central Pacific and eastern Indian Ocean.

Global teleconnections for TC days revealed three substantial correlations. The southern Pacific Ocean (SPAC100; $40^{\circ}-65^{\circ} \mathrm{S}, 170^{\circ}-140^{\circ} \mathrm{W}$ ) January-March $100-\mathrm{hPa}$ wind $v$ component is moderately correlated $(+0.52$, Fig. 9a). The North America April-June 850-hPa geopotential heights $\left(\mathrm{NA} 850 ; 30^{\circ}-50^{\circ} \mathrm{N}, 105^{\circ}-80^{\circ} \mathrm{W}\right)$ have a region of strong correlation over the western Great Lakes 
(a)

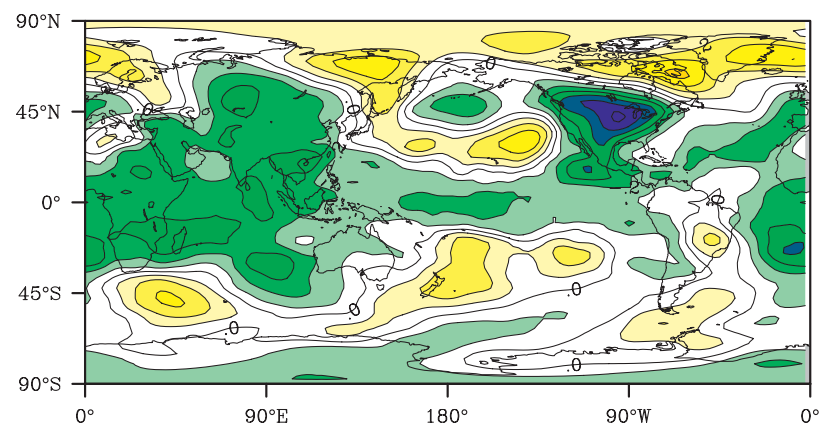

(c)

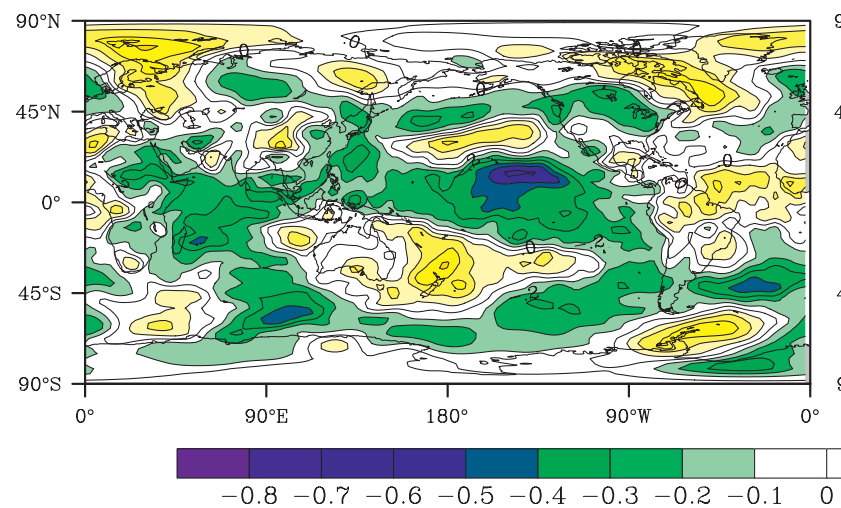

(b)

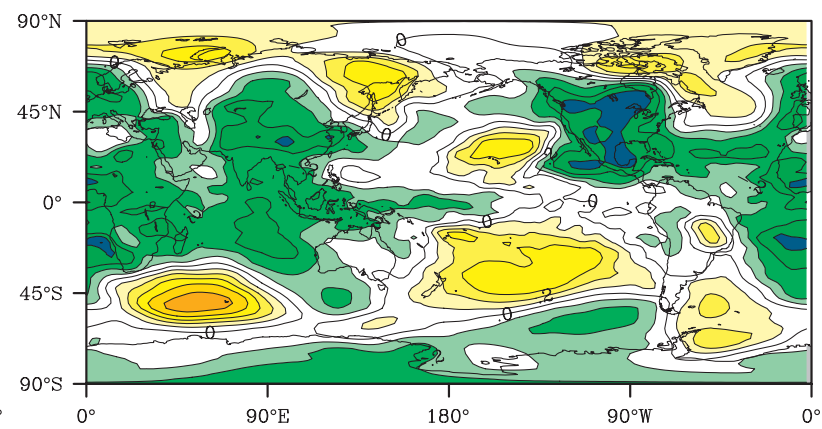

(d)

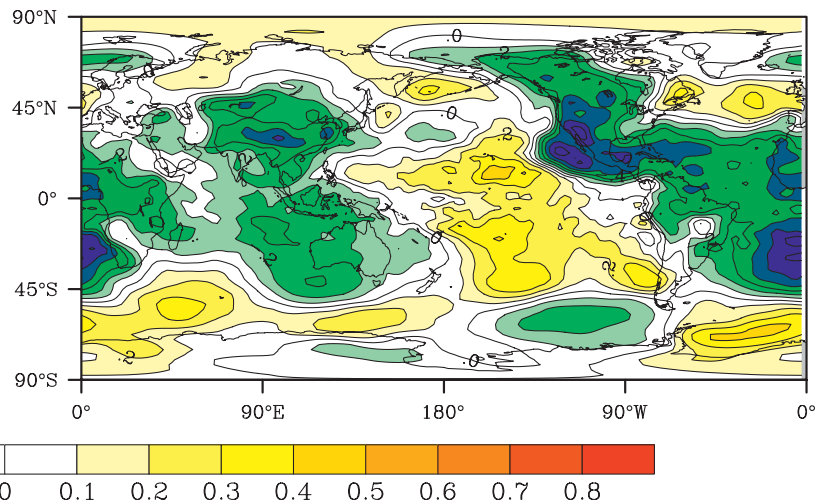

FIG. 8. Correlation maps between TC frequency and (a) April-June 700-hPa geopotential heights, (b) May-July 850-hPa geopotential heights, (c) May-July 850-hPa air temperature, and (d) June-August 925-hPa geopotential heights.

( -0.58 , Fig. 9 b). The NA850 region is linked to the NAO and AO, which are known to affect Northern Hemispheric climate patterns. Last, the South Atlantic Ocean 1000 -hPa heights (SATL1000; $5^{\circ}-45^{\circ} \mathrm{S}, 35^{\circ} \mathrm{W}-10^{\circ} \mathrm{E}$ ) exhibit a high correlation of -0.7 (Fig. 9c).

\section{d. Preliminary seasonal experiments}

Preliminary results confirm the expectation that skillful seasonal predictions for the NWAUS region can be achieved for both TC frequency and TC days using the predictors identified in the previous section. Application of a multiple linear regression (MLR) scheme was used to generate the intercept parameter and coefficients for each predictor, from a subset of the 39-yr dataset. For TC frequency prediction, $28 \mathrm{yr}$ of development data (Goebbert 2009) were required to create the following stable prediction equation:

$$
\begin{aligned}
\mathrm{TC}_{\text {freq }}= & 5.5714-0.8826 \times \mathrm{NA} 700-0.5763 \times \mathrm{HI} 850 \\
& +0.5861 \times \mathrm{SIND} 850+0.4613 \times \text { EPAC925 } \\
& -0.804 \times \text { SATL925. }
\end{aligned}
$$

For TC days predictions, slightly more years (33) of the development dataset (Goebbert 2009) were required to produce the following stable prediction equation:

$$
\begin{aligned}
\mathrm{TC}_{\text {days }}= & 43.641-11.075 \times \mathrm{SATL} 1000-7.851 \times \mathrm{NA} 850 \\
& +6.997 \times \mathrm{SPAC} 100
\end{aligned}
$$

The skill of both prediction equations was evaluated relative to two commonly employed baseline predictions, persistence, and climatology. In the case of the years used for the equation development, cross validation is used to create a longer prediction record. The skill score (SS) used here to assess predictive skill over climatology was

$$
\mathrm{SS}=1-\frac{\mathrm{MSE}}{\mathrm{MSE}_{\mathrm{ref}}}
$$

where MSE is the mean square error of the hindcast predictions and $\mathrm{MSE}_{\text {ref }}$ is the MSE of a reference forecast (Wilks 2005). The results of the comparison are shown in Table 4, with the SS converted to percentages. They clearly reveal the superiority of the MLR scheme. The MSE for the TC frequency prediction is 1.99 and for the climatology prediction MSE is 5.52, which is a $64 \%$ skill score (SS) gain for the MLR scheme over climatology (Table 4). For persistence, the MSE is 7.67, which is a $74 \%$ SS gain (Table 4). For TC days a similar improvement over a climatological prediction was observed in 
(a)

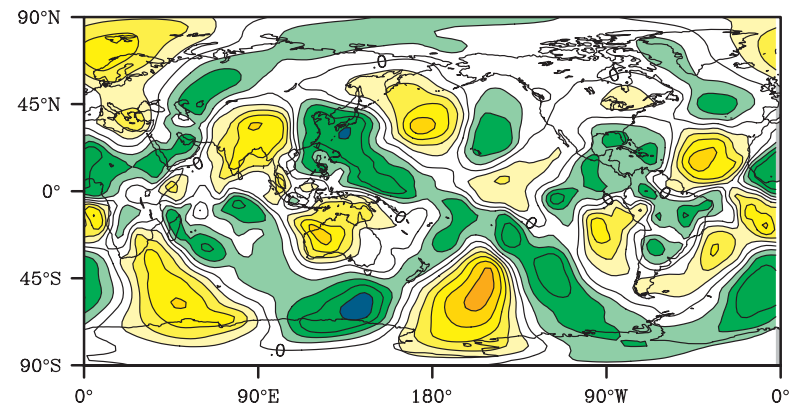

(b)

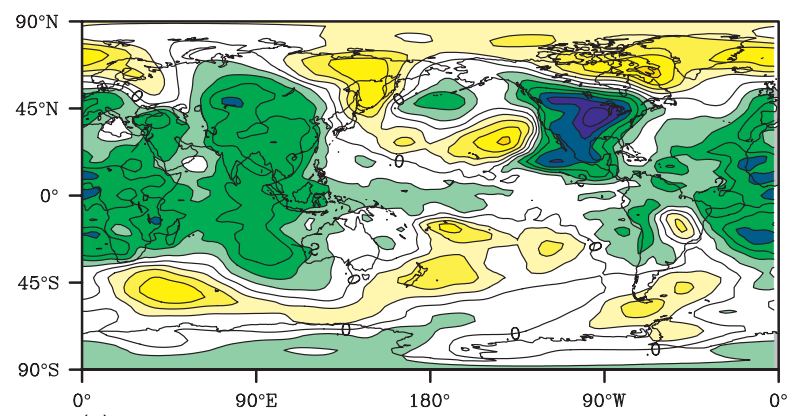

(c)

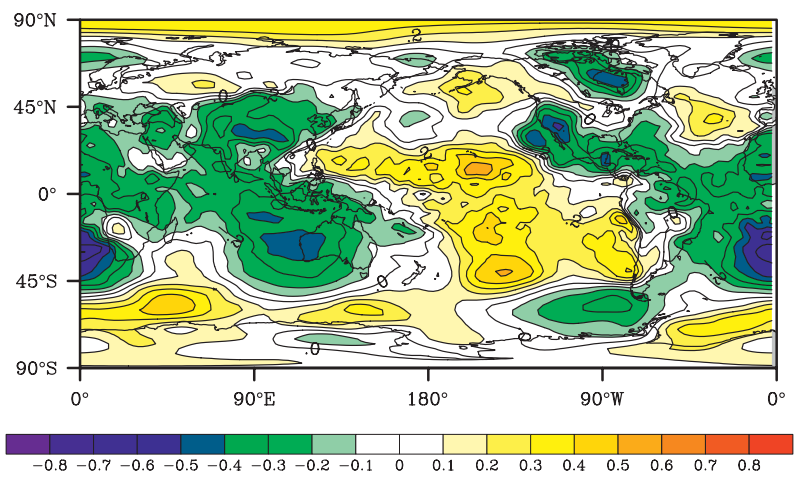

FIG. 9. Correlation maps between TC days and (a) JanuaryMarch 100-hPa $v$ component of the wind, (b) April-June 850-hPa geopotential heights, and (c) July-September 1000-hPa geopotential heights.

the MSE of 144.72 for MLR and of 388.88 and 586.61 for climatology and persistence, respectively. The SS gains of the MLR TC days prediction equation were also large, being $63 \%$ and $75 \%$ gains over climatology and persistence, respectively (Table 4).

\section{Discussion}

A detailed study of TC metrics in the NWAUS region revealed little interannual variability. Trends in TC frequency are similar to those obtained by Nicholls et al. (1998) for the entire Australian region. For intense TCs (i.e., TCs with central pressures $<970 \mathrm{hPa}$ ), Nicholls et al. (1998) found only a slight increase in the number of
TABLE 4. Observed MSEs for persistence, climatology, and MLR TC frequency and TC days predictions, for the NWAUS region over the period 1970-2008. The corresponding SSs are expressed as percentage improvements of MLR.

\begin{tabular}{llllll}
\hline \hline & \multicolumn{2}{c}{ TC frequency } & & \multicolumn{2}{c}{ TC days } \\
\cline { 2 - 3 } & MSE & SS & & MSE & SS \\
\hline Persistence & 7.67 & 74 & & 586.61 & 75 \\
Climatology & 5.52 & 64 & & 388.88 & 63 \\
MLR prediction & 1.99 & & & 144.72 & \\
\hline
\end{tabular}

intense TCs between 1969 and 1994, while the present study revealed no trend in the number of intense TCs for the NWAUS subbbasin (Fig. 2a). The difference could be due to the basins studied or to a longer-term trend only partially observed in the shorter, earlier Nicholls et al. (1998) dataset. Ramsay et al. (2008) found a similar trend to Nicholls et al. for a subset of their dataset (1970-2006). A similar lack of significant trends was obtained for other NWAUS TC metrics.

Recently, Kuleshov et al. (2010) confirmed the earlier results of Kuleshov et al. (2008) that observed no linear trend in the occurrence of all TCs for 1981-2006 over the entire Southern Hemisphere. They observed an upward trend in intense TCs, with minimum pressures $<945$ and $<965 \mathrm{hPa}$ for the entire Southern Hemisphere and the South Indian Ocean, respectively. In this study, our highest intensity category was for cyclones with minimum central pressures $<970 \mathrm{hPa}$ and, like Kuleshov et al. (2010), the linear trends were not significant. None of the TC metrics investigated in this study exhibited a significant linear trend. Kuleshov et al. (2010) suggests that, even with the 1981-2006 TC seasons, it is difficult to ascertain if any long-term trends are significant, owing to data inhomogeneity. Additionally, with a relatively short data period, it is difficult to determine the significance of any trend, unlike the North Atlantic region which has had reconnaissance and regular satellite observations over a much longer time span. The choice and length of the TC dataset is important because, depending on where a TC frequency time series is split, any observed trend can become reversed or flat, as pointed out by Ramsay et al. (2008, 1096-1097).

The results of this study suggest, through correlations obtained with geopotential height, air temperature, and components of the wind, that there are teleconnections modulating the frequency of TCs and TC days in the NWAUS region. However, known climate indices-such as Niño-3.4, Niño-4, SOI, NOI, PDO, NAO, and othersgenerally were found not to be significantly correlated to the variability of TC frequency or TC days in the NWAUS region. Previous strong teleconnections with Niño-3.4 and Niño-4 SST regions were found to be only 
marginally significantly correlated to NWAUS TC frequency and TC total seasonal days. In contrast, Ramsay et al. (2008) found significant correlations between TC frequency in the entire Australian region and central Pacific SSTs. In the SWPAC Ocean, Basher and Zheng (1995) found a strong relationship between the ENSOrelated variables and TC frequency for a number of subbasins. For the NWAUS subbasin, correlations with standard ENSO variables are substantially lower before, during, and after the TC seasons. Other studies have used standard ENSO-related parameters, such as SOI, to predict the number of TCs and TC days for the Australian region (Nicholls 1979). In this study, like Broadbridge and Hanstrum (1998), the SOI does not explain a substantial amount of variation in either TC frequency or TC days of the NWAUS region.

Other global teleconnections not directly linked to ENSO are identified for both NWAUS TC frequency and TC days. Much more research exists for Northern Hemispheric teleconnections, which affect TC tracks and other TC metrics. One teleconnection pattern used to explain variability of hurricane frequency in the Atlantic region is the QBO (Gray 1984a; Gray et al. 1992). However, this study found no similar link between the QBO and variability of TC frequency or TC days in the NWAUS region.

Other global teleconnections are not significantly correlated to the TC frequency or TC days in the NWAUS region. Some modes (e.g., NAO and AO) that were investigated were not developed for the NWAUS region and do not capture the atmospheric and oceanic variability influencing the NWAUS basin. A more encompassing approach may be to search for new correlations in the global reanalysis data. Studies of the North Atlantic region have identified global teleconnections for seasonal predictions in both Northern and Southern Hemispheres (e.g., Klotzbach and Gray 2003). In the Australian region, McDonnell and Holbrook (2004a) used the six parameters of Gray (1968), but their predictions were for individual cyclones, not seasonal, basinwide forecasts. To search for parameters that explain the variance of TC frequency and TC days in the NWAUS region, global NCEP-NCAR reanalysis data were used to identify areas where variables such as geopotential heights, air temperature, wind, and SSTs are strongly correlated with annual TC frequencies and TC days. These variables also are related to large-scale vertical wind shear and were shown by Dare and Davidson (2004) to be important to TC formation in the Australian region. However, links between the extratropics and the tropics through global teleconnections remain poorly understood.

The set of highly correlated base-state variables from the NCEP-NCAR reanalysis are candidates for a seasonal prediction scheme of TC frequency and TC days in the
NWAUS region. Although earlier studies of the NWAUS and entire Australian region (Nicholls 1979, 1985, 1992; Solow and Nicholls 1990; Nicholls et al. 1998; Broadbridge and Hanstrum 1998) used only ENSOrelated variables, a broader multivariate approach may produce an effective seasonal prediction scheme using the teleconnections identified in this study. Preliminary results, presented in section $3 \mathrm{~d}$, indicate that successful seasonal predictions can be accomplished using a simple MLR approach.

\section{Conclusions}

This study is a comprehensive analysis of the variability of TC metrics over the northwest Australian TC subbasin, referred to here as NWAUS. Using the Woodside Petroleum Ltd. (WPL) reanalysis TC dataset (Harper et al. 2008), we investigated the variability of 13 different TC metrics for the NWAUS region. Most attention was on the variability of TC frequency and TC days, as the most commonly used TC metrics. Unlike other basins (e.g., the North Atlantic and southwest Pacific basins), none of the 13 NWAUS TC metrics exhibited statistically significant linear trends.

A notable shift in the global atmospheric patterns of geopotential height and sea surface temperatures was observed between the 13 most active and 10 most inactive seasons, as defined by seasonal TC numbers. Additionally, climate indices and NCEP-NCAR reanalysis data were investigated to delineate areas exhibiting similar variances in TC frequency and TC days prior to the beginning of the TC season. Most climate indices were not significantly correlated with TC frequency or TC days prior to the beginning of the TC season. This study, like that of Broadbridge and Hanstrum (1998), revealed that standard ENSO parameters do not substantially explain the variability in either TC frequency or TC days of the NWAUS region. Other global modes not directly linked to ENSO are identified for both TC frequency and TC days, but the correlations are only small to moderate. However, global reanalyses identified regions of significant correlations with both annual TC frequency and TC days. For TC frequency, five areas of correlations of $\sim 0.6$ or higher magnitude were found. For TC days, there were three areas of $\sim 0.6$ or higher magnitude, the largest reaching 0.7 .

A further correlation of interest is that the mean number of TCs is highly correlated $(r \sim-0.67)$ with the season start date, but is not significantly correlated with season end date $(r \sim+0.2)$. This season start date correlation could prove useful in predicting how active a TC season might be, and can be included in intraseasonal TC prediction schemes. 
Wavelet analyses using two different mother wavelets (Morlet and Mexican Hat) revealed periodicities on ENSO and decadal time scales of 4-6 and 12-14 yr, respectively. Multidecadal periodicities are not identifiable, as the $39 \mathrm{yr}$ (1970-2008) of the most reliable TC time series for the NWAUS subbasin is too short for conclusions to be drawn.

Future work will continue to refine seasonal predictions of TC frequency and TC days over the NWAUS region, with lead times of up to 6 months, using a range of statistical techniques. Additionally, the predictions will be enhanced to include a fuller complement of seasonal TC metrics.

Acknowledgments. The authors thank Woodside Petroleum Ltd.-specifically Stan Stroud-for providing partial funding for this research and the TC dataset. Additional funding came from the School of Meteorology at OU through the Lowry Chair. The authors would also like to thank Sean Arms for assistance with the wavelet analysis. Finally, the authors thank the three anonymous reviewers, whose comments greatly improved this manuscript.

\section{REFERENCES}

Ambaum, M. H., B. J. Hoskins, and D. B. Stephenson, 2001: Arctic Oscillation or North Atlantic Oscillation? J. Climate, 14, 34953507.

Baldwin, M. P., and Coauthors, 2001: The quasi-biennial oscillation. Rev. Geophys., 39, 179-229.

Barnston, A. G., and R. E. Livezey, 1987: Classification, seasonality and persistence of low-frequency atmospheric circulation patterns. Mon. Wea. Rev., 115, 1083-1126.

Basher, R. E., and X. Zheng, 1995: Tropical cyclones in the southwest Pacific: Spatial patterns and relationships to Southern Oscillation and sea surface temperature. J. Climate, 8, 1249 1260.

Bell, G. D., M. S. Halpert, C. F. Ropelewski, V. E. Kousky, A. V. Douglas, R. S. Schnell, and M. E. Gelman, 2000: Climate assessment for 1999. Bull. Amer. Meteor. Soc., 81, S1-S50.

BOM, cited 2010: Bureau of Meteorology current tropical cyclones. [Available online at http://www.bom.gov.au/weather/ cyclone/faq/index.shtml.]

Bretherton, C. S., M. Widmann, V. P. Dymnikov, J. M. Wallace, and I. Blade, 1999: The effective number of spatial degrees of freedom of a time-varying field. J. Climate, 12, 1990-2009.

Broadbridge, L. W., and B. N. Hanstrum, 1998: The relationship between tropical cyclones near Western Australia and the Southern Oscillation Index. Aust. Meteor. Mag., 47, 183-189.

Buckley, B. W., L. M. Leslie, and M. S. Speer, 2003: The impact of observational technology on climate database quality: Tropical cyclones in the Tasman Sea. J. Climate, 16, 2640-2645.

Chan, J. C. L., 1985: Tropical cyclone activity in the northwest Pacific in relation to the El Niño/Southern Oscillation phenomenon. Mon. Wea. Rev., 113, 599-606.

, and K. S. Liu, 2004: Global warming and western North Pacific typhoon activity from an observational perspective. J. Climate, 17, 4590-4602.
_ J. E. Shi, and C. M. Lam, 1998: Seasonal forecasting of tropical cyclone activity over the western North Pacific and the South China Sea. Wea. Forecasting, 13, 997-1004.

Dare, R. A., and N. E. Davidson, 2004: Characteristics of tropical cyclones in the Australian region. Mon. Wea. Rev., 132, 30493065.

Dvorak, V. F., 1984: Tropical cyclone intensity analysis using satellite data. NOAA Tech. Rep. NESDIS 11, 47 pp. [Available from NOAA/NESDIS, 5200 Auth Rd., Washington, DC 20233.]

Elsner, J. B., and B. Kocher, 2000: Global tropical cyclone activity: A link to the North Atlantic Oscillation. Geophys. Res. Lett., 27, 129-132.

Evans, J. L., and R. J. Allan, 1992: El Niño/Southern Oscillation modification to the structure of the monsoon and tropical cyclone activity in the Australiasian region. Int. J. Climatol., 12, 611-623.

Frank, W. M., and G. S. Young, 2007: The interannual variability of tropical cyclones. Mon. Wea. Rev., 135, 3587-3598.

Gershunov, A., and T. P. Barnett, 1998: Interdecadal modulation of ENSO teleconnections. Bull. Amer. Meteor. Soc., 79, 27152725.

Glickman, T., Ed., 2000: Glossary of Meteorology. 2nd ed. Amer. Meteor. Soc., 855 pp.

Goebbert, K. H., 2009: Northwest Australian tropical cyclones: Variability and seasonal prediction. Ph.D. thesis, University of Oklahoma, 159 pp.

Goodrich, G. B., 2007: Influence of the Pacific decadal oscillation on winter precipitation and drought during years of neutral ENSO in the western United States. Wea. Forecasting, 22, 116-124.

Gray, W. M., 1968: Global view of the origin of tropical disturbances and storms. Mon. Wea. Rev., 96, 669-700.

_ 1984a: Atlantic seasonal hurricane frequency. Part I: El Niño and $30 \mathrm{mb}$ quasi-biennial oscillation influences. Mon. Wea. Rev., 112, 1649-1668.

_ 1984 b: Atlantic seasonal hurricane frequency. Part II: Forecasting its variability. Mon. Wea. Rev., 112, 1669-1683.

_ C. W. Landsea, P. W. Mielke Jr., and K. J. Berry, 1992: Predicting Atlantic seasonal hurricane activity 6-11 months in advance. Wea. Forecasting, 7, 440-455.

,,,--- and -1993 : Predicting Atlantic basin seasonal tropical cyclone activity by 1 August. Wea. Forecasting, 8, 73-86.

Hall, J. D., A. J. Matthews, and D. J. Karoly, 2001: The modulation of tropical cyclone activity in the Australian region by the Madden-Julian oscillation. Mon. Wea. Rev., 129, 2970-2982.

Harper, B. A., S. A. Stroud, M. McCormack, and S. West, 2008: A review of historical tropical cyclone intensity in northwestern Australia and implications for climate change trend analysis. Aust. Meteor. Mag., 57, 121-141.

Hastings, P. A., 1990: Southern Oscillation influences on tropical cyclone activity in the Australian/southwest Pacific region. Int. J. Climatol., 10, 291-298.

Higgins, R. W., A. Leetmaa, Y. Xue, and A. Barnston, 2000: Dominant factors influencing the seasonal predictability of U.S. precipitation and surface air temperature. J. Climate, 13, 39944017.

Holland, G. J., 1981: On the quality of the Australian tropical cyclone data base. Aust. Meteor. Mag., 29, 169-181.

Hurrell, J. W., 1995: Decadal trends in the North Atlantic Oscillation: Regional temperatures and precipitation. Science, 269, 676-679.

Kalnay, E., and Coauthors, 1996: The NCEP/NCAR 40-Year Reanalysis Project. Bull. Amer. Meteor. Soc., 77, 437-471. 
Klotzbach, P. J., and W. M. Gray, 2003: Forecasting September Atlantic basin tropical cyclone activity. Wea. Forecasting, 18, 1109-1128.

— basin seasonal hurricane activity. Wea. Forecasting, 19, 917-934.

Kuleshov, Y., L. Qi, R. Fawcett, and D. Jones, 2008: On tropical cyclone activity in the Southern Hemisphere: Trends and the ENSO connection. Geophys. Res. Lett., 35, L14S08, doi:10.1029/ 2007GL032983.

_ , R. Fawcett, L. Qi, B. Trewin, D. Jones, J. McBride, and H. Ramsay, 2010: Trends in tropical cyclones in the South Indian Ocean and the South Pacific Ocean. J. Geophys. Res. 115, D01101, doi:10.1029/2009JD012372.

Lander, M. A., and C. P. Guard, 1998: A look at the global tropical cyclone activity during 1995: Contrasting high Atlantic variability with low activity in other basins. Mon. Wea. Rev., 126, 1163-1173.

Landsea, C. W., 2000: Climate variability of tropical cyclones: Past, present and future. Storms, R. A. Pielke Sr. and J. R. A. Pielke, Eds., Routledge, 220-241.

Larson, E., 2000: Isaac's Storm: A Man, a Time, and the Deadliest Hurricane in History. Knopf Publishing Group, 336 pp.

Love, G., 1985: Cross-equatorial interactions during tropical cyclogenesis. Mon. Wea. Rev., 113, 1499-1509.

Mantua, N. J., S. R. Hare, Y. Zhang, J. M. Wallace, and R. C. Francis, 1997: A Pacific interdecadal climate oscillation with impacts on salmon production. Bull. Amer. Meteor. Soc., 78, 10691079.

McDonnell, K. A., and N. J. Holbrook, 2004a: A Poisson regression model of tropical cyclogenesis for the Australian-southwest Pacific Ocean region. Wea. Forecasting, 19, 440-455.

Nicholls, N., 1979: A possible method for predicting seasonal tropical cyclone activity in the Australian region. Mon. Wea. Rev., 107, 1221-1224.

_ 1984: The southern oscillation, sea-surface temperature, and interannual fluctuations in Australian tropical cyclone activity. J. Climatol., 4, 661-670.

- 1985: Predictability of interannual variations of Australian seasonal tropical cyclone activity. Mon. Wea. Rev., 113, 1144 1149.
1992: Recent performance of a method for forecasting Australian season tropical cyclone activity. Aust. Meteor. Mag., 40, $105-110$

_ _ C. Landsea, and J. Gill, 1998: Recent trends in Australian region tropical cyclone activity. Meteor. Atmos. Phys., 65, 197-205.

Ramsay, H. A., L. M. Leslie, P. J. Lamb, M. B. Richman, and M. Leplastrier, 2008: Interannual variability of tropical cyclones in the Australian region: Role of large-scale environment. J. Climate, 21, 1083-1103.

Revell, C. G., and S. W. Goulter, 1986: South Pacific tropical cyclones and the Southern Oscillation. Mon. Wea. Rev., 114, 1138-1145.

Saji, N. H., B. N. Goswami, P. N. Vinayachandran, and T. Yamagata, 1999: A dipole mode in the tropical Indian Ocean. Nature, 401, 360-363.

Schwing, F., T. Murphree, and P. Green, 2002: The Northern Oscillation Index (NOI): A new climate index for the northeast Pacific. Prog. Oceanogr., 53, 115-139.

Smith, T. M., and R. W. Reynolds, 2004: Improved extended reconstruction of SST (1854-1997). J. Climate, 17, 2466-2477.

Solow, A., and N. Nicholls, 1990: The relationship between the Southern Oscillation and tropical cyclone frequency in the Australian region. J. Climate, 3, 1097-1101.

Thompson, D. W., and J. M. Wallace, 1998: The Arctic Oscillation signature in wintertime geopotential height and temperature fields. Geophys. Res. Lett., 25, 1297-1300.

Torrence, C., and G. P. Campo, 1998: A practical guide to wavelet analysis. Bull. Amer. Meteor. Soc., 79, 61-78.

Trewin, B., 2008: An enhanced tropical cyclone data set for the Australian region. Preprints, 20th Conf. on Climate Variability and Change, New Orleans, LA, Amer. Meteor. Soc., JP3.1. [Available online at http://ams.confex.com/ams/pdfpapers/ 128054.pdf.]

Walker, G. T., and E. W. Bliss, 1932: World Weather V. Mem. Roy. Meteor. Soc., 4, 53-84.

Wallace, J. M., and D. S. Gutzler, 1981: Teleconnections in the geopotential height field during the Northern Hemisphere winter. Mon. Wea. Rev., 109, 784-812.

Wilks, D. S., 2005: Statistical Methods in the Atmospheric Sciences. 2nd ed. Academic Press, 648 pp.

Zhang, Y., J. M. Wallace, and D. S. Battisti, 1997: ENSO-like interdecadal variability: 1900-93. J. Climate, 10, 1004-1020. 